\title{
Vertical Channel Conflict Coordination Strategy of e-Commerce Supply Chain under Platform Brand Empowerment
}

\author{
Di Xiao, ${ }^{1,2}$ Qianqian Yang, ${ }^{1}$ Qi Sun $\mathbb{D}^{1,2}$ and Huimin Fang ${ }^{1}$ \\ ${ }^{1}$ School of Business Administration, Zhejiang Gongshang University, Hangzhou 310018, China \\ ${ }^{2}$ Research Center of Modern Business and Trade, Zhejiang Gongshang University, Hangzhou 310015, China \\ Correspondence should be addressed to Qi Sun; 344497713@qq.com
}

Received 23 July 2021; Accepted 16 September 2021; Published 5 October 2021

Academic Editor: Weilin Xiao

Copyright (C) 2021 Di Xiao et al. This is an open access article distributed under the Creative Commons Attribution License, which permits unrestricted use, distribution, and reproduction in any medium, provided the original work is properly cited.

We develop a game model for a supply chain consisting of one e-commerce platform, one supplier from other channels, and one retailer. The platform has a well-known brand that can influence consumers' purchase decisions, and it provides good-quality products with high prices, while supplier from other channels provides cheaper products but possibly with low quality, and there may even be some serious quality problems, sometimes leading to serious problems such as "free-riding" behavior by the retailer and reducing the profits of the supply chain members. First, we study the decisions of platform and retailer under centralized decision (CD) scenario, decentralized decision (DD) scenario, cost sharing contract (CS) scenario, and minimum order quantity contract (QC) scenario. Second, we found that channel conflicts have a negative impact on supply chain members under DD scenario; however, CS and QC scenarios can make the optimal empowerment level of platform the same as CD scenario and encourage retailer to order more products from platform. Finally, the improvement effect in QC and CS scenarios is affected by the substitutability of the two products, the coefficient of empowerment cost, and the reaction coefficient of product price on goodwill. Furthermore, we found that under QC scenario, only within an appropriate range can the platform and the retailer achieve a winwin situation.

\section{Introduction}

In recent years, with the continuous development of information technology, e-commerce platforms have developed rapidly. In the United States, Amazon has become the largest e-commerce company after decades of development and has transformed from an online bookstore to a comprehensive e-commerce platform. Especially, its sales revenue is 280.52 billion dollars in 2019, which is more than 8 times as much as that of 2010 (https://www.touzhibang.com/ 1132.html). Similarly, Alibaba is in a leading position in China's e-commerce market with $55.9 \%$ sales share in 2019 (https://www.iimedia.cn/c1061/71838.html). However, as the competition intensifies, the profit growth of online retailers begins to slow down. For example, though e-commerce sales in the United States reached $\$ 599$ billion in 2019, the growth rate has slowed in recent years, and even declined in 2017 and 2018 (https://www.199it.com/archives/1148207. html). In order to compensate for the decline in profits from online channels, e-commerce platforms have tried to expand offline channels. The impact of e-commerce platforms and the competitive pressure of peers make offline retail stores face severe challenges, especially in some small cities, towns, and even villages, although there are abundant customer demands in the offline market, retail stores that are run by individuals lack brand influence and management, and they have no advantage in market competition. Therefore, they also hope to get the help of e-commerce platforms to obtain high-quality products and enhance the brand image. Then, e-commerce platforms begin to export brands and information technology to retail stores to expand offline channels, and the retail stores often accept the help of e-commerce platforms in order to increase their profits. We define this type of behavior made by e-commerce platform as "empowerment," which means the platform use big data analysis, brand effects, integrated services, and other means to 
improve other participants' capabilities in the enhancement of brand influence, data utilization and user perception, so as to improve the overall operational performance of e-commerce supply chains. For example, Alibaba cooperates with offline retailers so that they can use Ali's digital tools and solutions to understand consumers' purchase preferences and optimize the delivery of goods to attract new consumers, instead of just selling products on Ali's platforms.

In practice, there are many forms of empowerment, among which "brand empowerment" is an emerging way. The platform brand empowerment (PBE) mainly refers to the platform empowers the retail store with more wellknown e-commerce platform brand, while providing some popular products available only on e-commerce platform's channels, which help retail stores enhance brand influence in order to attract more customers and win customers' trust. At the same time, the e-commerce platform can achieve online and offline integration, such as JD.com formulated the "JD Convenience Store" plan in 2017, followed by Ali and Suning also launched "Tmall Convenience Store" and "Suning Convenience Store" respectively, using their own advantages to empower offline retail stores with brand. Taking JD New Channel as an example, it has abundant commodities and powerful supply chain resources of JD.com and provides professional terminal services and data support for smalland medium-sized retail stores, so it launched JD Convenience Store. It can rely on its own resources to promote cooperation between JD Convenience Store and well-known companies, such as Unilever, to optimize the depth of distribution, brand promotion, and preferential promotion. In addition, it can provide JD Convenience Stores with operational planning based on consumption scenarios, which include product types, store layouts, and marketing plans with characteristics of JD.com, and regular improvement suggestions by analyzing relevant data of surrounding consumers. Through these measures, the retail stores improve their abilities to accurately analyze what kind of products are marketable and provide more personalized service to consumers so that consumers' experience and the efficiency of store are both improved. Furthermore, JD.com also expands its brand's influence and directs more customers' demands from offline to online.

However, PBE is still in the primary stage of development and e-commerce platform does not have enough power to restrict the behaviors of retailer. Due to the existence of opportunism, retailer may order some counterfeit products with cheaper wholesale price from other channels, which are similar to genuine products but of poor quality and sell them to consumers in the name of platform, and the "free-riding" behavior will hurt the interests of consumers; it may even endanger their health and safety, which will also greatly damage the platform's brand goodwill. As a result, there is a channel conflict that means although channel members depend on each other, they often dispute over what kind of benefits they want to get. Obviously, different opinions on goals, roles, and returns often lead to channel conflicts [1]. In practice, JD.com allows retailers to order less than $50 \%$ of products from other channels and requires them to pay a warranty of 5,000 to 20,000 yuan to ensure that the products are $100 \%$ free of counterfeits, while there are no other specific measures to prevent the inflow of counterfeits. Although the products provided by JD.com are of good quality, the wholesale price is higher, so some retailers order counterfeit products from other channels with lower wholesale prices for their own interests. Once consumers buy these counterfeits from convenience stores, they will think that there is a problem with the quality of JD.com's products, and its brand image will be seriously damaged. Therefore, our study attempts to address the following questions:

(1) How much negative impact will vertical channel conflicts bring to supply chain members?

(2) What are the optimal ordering decisions of retailer and optimal empowerment level of platform in some common scenarios?

(3) Can the supply chain incentive mechanism encourage the retailer to order more products from the platform and reduce vertical channel conflicts?

We construct a single-cycle and two-echelon supply chain consisting of one e-commerce platform, one retailer and one supplier from other channels, and try to solve the channel conflicts under PBE and improve the decisions of platform and retailer. First, we found that channel conflicts affect the decisions of supply chain members and decrease the profits, especially in decentralized decision (DD) scenario. Second, we studied the effect of the contracts on the supply chain with empowerment cost sharing contract (CS) and minimum order quantity contract (QC), where CS means e-commerce platform determines cost sharing ratio and level of PBE, and QC scenario refers to that e-commerce platform determines the level of PBE and designs the reward and punishment mechanism for the retailer's ordering decisions. We conclude that both contracts can induce retailer to accept cooperation, increase the quantity of products that retailer order from the platform, and have an equal role in increasing the level of PBE. Finally, through comparison, we find that $\mathrm{CD}$ scenario is always the best choice for the supply chain members. At the same time, QC scenario plays a greater role in reducing channel conflicts; however, it is necessary for the platform to design appropriate reward and punishment mechanism.

The remainder of the paper is organized as follows: Section 2 reviews the relevant research studies. Section 3 mainly introduces the model assumptions and the meanings of various symbols in the article. Section 4 discusses the impact of the empowerment cost sharing contract and minimum order quantity contract on supply chain decisionmaking and performance. Section 5 compares and analyzes the optimal decisions and profits. Section 6 uses numerical simulation to illustrate the conclusions of the proposed model. Section 7 concludes the article and points out the shortage and suggested the future research directions.

\section{Literature Review}

This article is closely related to platform empowerment, channel conflict, supply chain contract, and other fields. To emphasize our contribute in the research, we review some representative literature in this part. 
2.1. Platform Empowerment. The concept of "empowerment" was first proposed by the field of positive psychology. Later, the researches extended to management, which initially focused on the individual and were considered to delegate decision-making power to subordinates [2]. Then, empowerment on the organizational level was gradually rising, which means the organization provides resources to support employees or teams. With the rapid development of the platform economy, empowerment is applied to platform. Most researchers have studied data empowerment (PDE), which refers to the concept that platform empowers the suppliers, customers, and other participants through intelligence capability, connect capability, and analytic capability [3], and improves their data analysis capabilities and information utilization capabilities.

However, there are few literature studies directly studying PBE. The closest concept to PBE is the retailer's store brand. According to PLMA (Private Label Manufacturers Association), store brand or private brand are the products that carry the retailer's name or private brands. It can help retailers improve bargaining power and increase customers' loyalty $[4,5]$, while most of them have product quality problems, for example, Wal-Mart and IKEA have experienced quality problems with their own brand products. Three different extended warranty contracts [6] and money-back guarantees provided by retailers [7] can effectively improve the quality of these products and increase supply chain profits.

The existing literatures mainly study the empowerment behaviors from the aspects of psychology and resources, while rarely discuss the impact of empowerment behaviors, especially $\mathrm{PBE}$, on the operational decisionmaking and performance of e-commerce supply chain members. Our study conducts quantitative analysis and research under the context of PBE by constructing mathematical models to enrich existing research and solve more practical problems.

2.2. Counterfeit Product and Goodwill. Our study is related to the previous works on counterfeit product, which refers to these products that are very similar to the genuine products and sneak into the supply chain for sale at an equivalent price and consumers cannot easily distinguish $[8,9]$. Counterfeiters always benefit from their products because they can be sold at high prices with relatively low cost. In particular, when product infringement is deceptive or the counterfeit portion of the market is high, counterfeiters can obtain free rides with improved quality [10]. However, goodwill of enterprise, which is one of the strategic resources and intangible assets for it to form a sustainable competitive advantage, is vulnerable to damage $[11,12]$. Most existing studies believe that the level of enterprise's goodwill is affected by the quality of the products and the level of advertising [13-15], when enterprise's goodwill level is higher, the competition based on product quality will be more intense [16] and the higher the degree of product defects will have a greater negative impact [17]. Thus, it is very important to prevent counterfeit products from entering the market and identify parties that may be involved in counterfeiting activities [18]. Qian [19] points that product differences have an impact on counterfeits; consumer purchase intentions [20] and government regulation strategies [21] are the same. In alleviating the problems of counterfeit products, the development of relevant laws [22], website recommendation systems [23], and RFID tags [24] are helpful.

Different from the most studies focusing on the measures taken by downstream enterprises to prevent counterfeiters from entering, this article mainly studies the quality control of the upstream platform on the products ordered by the downstream retailer and the incentive mechanisms established by platform to reduce the motivation of retailer to order counterfeit products from other channels.

2.3. Channel Conflicts. Channel conflict is defined as a situation that one channel member believes that the behaviors of other channel members threaten its profit, their interests are inconsistent, and the decisions are made to maximize their own interests $[25,26]$. The causes of channel conflict mainly include different role positioning [27], scarce resources [28], different objectives [29], and so on. Obviously, channel conflicts have a negative impact on channel performance [30, 31], such as reducing the satisfaction [32] and cooperation level [33] among channel members. In the context of e-commerce, the researches mainly focus on the horizontal channel conflict between online channels and offline channels, price competition [34-36], asymmetric information [37], and differences in service quality [38] between the two channels is fierce. Chen et al. [39] think that appropriate local advertising level can reduce conflicts between online and offline channels; adding value to products by retailers [40], adjusting the price difference between channels [41], and implementing segmentation and integration strategies all have the same effect [42].

When channel conflicts occur, traditional contracts cannot coordinate the supply chain. Tsay and Agrawal [43] studied the coordination of supply chain with benefit compensation contract. Also, through the improved revenue sharing contract $[44,45]$ and option contract [46], channel conflicts can be effectively reduced.

According to the relevant literatures, there are few related to vertical channel conflict; however, we study the vertical channel conflict between e-commerce platform and retailer in offline channel. Our article introduces the supply chain coordination contract into the new scenario of PBE, pays attention to the design of vertical conflict management mechanism, and considers the influence of goodwill on the result of contract coordination.

\subsection{Supply Chain Contract}

2.4.1. Cost Sharing Contract. As an effective supply chain coordination mechanism, cost sharing contract has been widely used in the field of supply chain management. 
Generally, it can achieve supply chain coordination when cost sharing ratio is within a reasonable range [47-49]. Moreover, cost sharing contract can not only improve quality of product in the supply chain [50] but also reduce price competition in dual channels [51].

2.4.2. Minimum Order Quantity Contract. The contract requires the retailers to have a minimum order quantity every time or within a certain period, and they can choose not to order $[52,53]$. The researches on the minimum order quantity contract can be divided into two categories. One considers the contract as a necessary constraint, which thinks that the retailer's order quantity must be greater than or equal to the critical value of the minimum order quantity [54-56]. The other is the current mainstream of researches that regards the contract as an incentive constraint, which effectively motivate retailers and suppliers and ultimately realize the coordination of the supply chain [57-59].

Our model first considers whether empowerment cost sharing contract and minimum order quantity contract that is seen as an incentive constraint can coordinate the supply chain compared with DD scenario under the context of PBE, and then studies which of the two contracts can improve the profit of supply chain members more.

This article has the following contributions to existing researches. First, existing researches on platform empowerment mainly focuses on platform data empowerment, while this study studies platform brand empowerment, exploring the retailer's ordering decisions and e-commerce platform's empowerment-level decision through quantitative analysis. Second, though Zhang and Zhang [60] construct a two-echelon supply chain to study channel conflicts with counterfeit products, they mainly discuss the impact of counterfeit products on consumers' perception of quality and price of products. Our research studies the vertical channel conflict between the platform and retailer and considers the impact of counterfeit products on the platform's loss of goodwill. Finally, we extend cost sharing contract and minimum order quantity contract to the vertical channel conflict management mechanism of the e-commerce supply chain in the context of platform brand empowerment and consider the impact of goodwill on the coordination results on the basis of traditional researches.

\section{Assumptions and Model Description}

We construct a single-cycle two-echelon supply chain model that includes one e-commerce platform (such as JD New Channel), one supplier from other channels, and one retailer (such as JD Convenience Store). We believe that the platform is strong and rich in resources, the products provided are of high quality and qualified, and the price is relatively expensive. However, the products from the supplier of other channels whose management level is low have a certain unqualified rate $\lambda$, and a single unqualified product will cause the loss of goodwill on the platform to be $c_{f}$. Thus, retailer order $q_{p}$ units of products from platform at wholesale price $w_{p}$ and $q_{s}$ units from other channels at wholesale price $w_{s}$, where the ratio to the total order quantity is $r$. We assume $w_{p}=w_{s}+u$ and $w_{p}>\lambda c_{f}$, where $u>0$ denotes that the wholesale price of platform's products is higher than that of other channels; at the same time, it is an exogenous variable and cannot be changed in the short term [55]. The latter is to ensure that the platform is profitable. The structure of supply chain considered is shown in Figure 1.

The market sale prices of the two products are $p_{p}$ and $p_{s}$, respectively. Because counterfeit products and genuine products have similar functions, the substitution rate between them is $\beta$, where $\beta \in(0,1]$ denotes that there must be competition between the two channel products, the smaller the $\beta$, the greater the product difference, the less price competition.

In the cooperation of the e-commerce platform and retail store, the platform provides retail store with the level of $\operatorname{PBE}\left(t_{p}\right)$ to help it enhance the influence and competitiveness of brand, where $t_{p}$ is considered as an endogenous variable because the platform needs to make decisions on the level of PBE. With the development of new retail, many e-commerce platforms have raised the exploitation of offline retail stores to a strategic position. PBE gradually presents the characteristics of continuity, diversification, and personalization. For example, in recent years, JD.com has continuously empowered offline retail stores through public relations and marketing activities in cooperation with famous brands, while Ali general provides customized marketing solutions for offline retail stores through "city partners" to improve the uniqueness of Tmall Convenience Store. In addition, $t_{p} \geq 0$ indicates that at least the brand of the platform does not harm the retailer. The empowerment cost function of the platform is $k t_{p}^{2} / 2[61,62]$, where $k$ is the cost coefficient of PBE, and $k>0$ denotes PBE definitely imposes costs on the platform.

In this article, the market demand is certain, we use the inverse demand function, assuming that the price functions of products provided by the platform and other channels are $p_{p}=a-q_{p}-\beta q_{s}+\gamma g$ and $p_{s}=a-q_{s}-\beta q_{p}+\gamma g$, respectively, which show the competition in the order quantity of products from the two channels and the positive effect of PBE on product price, which are widely adopted by literatures [63-66], especially, $g=\theta t_{p}$ indicates that PBE helps retailers enhance their brand power, where $\theta$ denotes the maximum of retailer's brand power and $\gamma$ denotes the reaction coefficient of product price to goodwill, which is always nonnegative. Furthermore, we assume that $k(\beta+1)>\theta^{2} \gamma^{2}$ and $k \geq\left[\theta \gamma\left(2 a-w_{s}-\lambda c_{f}\right)+2 \theta^{2} \gamma^{2}\right] /$ $(2(\beta+1))$ to ensure that the PBE level is nonnegative, and the value range is $[0,1]$.

The profit functions of the retailer and e-commerce platform are as follows. Especially, we do not consider the purchase cost of the platform from its suppliers or the production cost of supplier from other channels [60].

$$
\begin{aligned}
& \Pi_{R}=\left(p_{p}-w_{p}\right) q_{p}+\left(p_{s}-w_{s}\right) q_{s} ; \\
& \Pi_{p}=w_{s} q_{p}-\frac{k t_{p}^{2}}{2}-\lambda q_{s} c_{f} .
\end{aligned}
$$




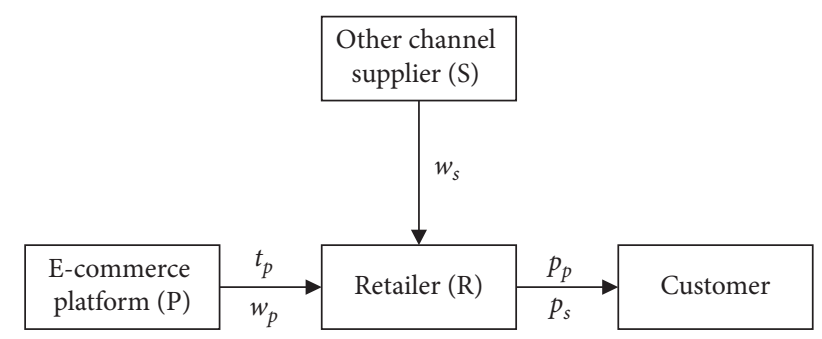

FIGURE 1: Two-echelon supply chain with vertical channel conflicts.

\section{Supply Chain Decisions}

In the following part, we discuss the centralized decision scenario as benchmark in Section 4.1 and decentralized decision scenario in Section 4.2, which explores whether $\mathrm{PBE}$ is adversely affected by independent decisions of supply chain members. Furthermore, Sections 4.3 and 4.4, respectively, study the role of empowerment cost sharing contract and minimum order quantity contract in reducing vertical channel conflicts.

4.1. CD Scenario. In the CD scenario, the e-commerce platform and retailer operate jointly as a unified whole. This is an ideal decision-making method, in which the decision is globally optimal and provides a benchmark for the improvement of the supply chain members under following scenarios. Decisions on product ordering and the level of $\mathrm{PBE}$ are made to maximize the whole supply chain profit.

Note that the total profits of platform and retailer in the CD scenario is as follows, which is the same as that under the CS and QC scenarios.

$$
\Pi_{\mathrm{CD}}=p_{p} q_{p}+\left(p_{s}-w_{s}\right) q_{s}-\frac{k}{2} t_{p}^{2}-\lambda q_{s} c_{f} .
$$

We conclude the equilibrium solutions in the CD scenario with Proposition 1, and all proofs in this study are provided in the Appendix.

Proposition 1. For the CD scenario, the equilibrium solutions are as follows:

(1) The PBE level is $t_{p}^{C D *}=\theta \gamma\left(2 a-w_{s}-\lambda c_{f}\right) / 2 K_{1}$.

(2) The order quantities from the platform and other channels are $q_{p}^{C D *}=\left[2 a k(1-\beta)+\left(w_{s}+\lambda c_{f}\right)(2 k \beta-\right.$ $\left.\left.\theta^{2} \gamma^{2}\right)\right] /\left(4(1-\beta) K_{1}\right)$ and $q_{s}^{C D *}=[2 a k \quad(1-\beta)$ $\left.-\left(w_{s}+\lambda c_{f}\right)\left(2 k-\theta^{2} \gamma^{2}\right)\right] /\left(4(1-\beta) K_{1}\right)$, respectively, where $2 a k(1-\beta)>\left(w_{s}+\lambda c_{f}\right)\left(2 k-\theta^{2} \gamma^{2}\right)$ and $K_{1}=k(1+\beta)-\theta^{2} \gamma^{2}, K_{1}>0$.

Corollary 1. The monotonicity of equilibrium solutions is as follows:

(1) $q_{p}^{C D *}$ increases with $c_{f}, q_{s}^{C D *}$ and $t_{p}^{C D *}$ decrease with $c_{f}$

(2) $q_{p}^{C D *}, q_{s}^{C D *}$, and $t_{p}^{C D *}$ increase with $\gamma$, decrease with $\beta$ and $k$
Corollary 1 (1) shows that the optimal quantity of products from platform increases with $c_{f}$, the reason is that the losses caused by counterfeit products will be greater when $c_{f}$ increases, so retailer will order more products from the platform in the CD scenario. However, the PBE level decreases with $c_{f}$ because with the increase of goodwill loss, the platform will reduce the cost by reducing the PBE level, so as to ensure its own profit.

Corollary 1 (2) indicates that the quantity of products from both channels and empowerment level increase with $\gamma$ but decrease with $\beta$ and $k$. The greater the $\gamma$, the higher the price of the product, so the profits of retailer and platform will increase when market demand is determined; thus, the quantity of products ordered by retailer from platform will increase, and the platform will also be willing to invest in the PBE. Regarding the substitutability of the two products, the higher it is, the more intense the product competition, and the profit of retailer decreases because of low price. Then, the retailer will buy more products from other supplier with lower wholesale prices. This means that with high product substitution, PBE encourages retailer to order more products from other channels, which will decrease the empowerment level and hurt platform's profit. Also, there is an intuitive conclusion that the empowerment level is inversely related to the $k$, which is the higher the empowerment cost coefficient, the lower the platform's empowerment level.

4.2. DD Scenario. In the DD scenario, the e-commerce platform and the retailer with decentralized decision are pursuing their own interests to maximize. The corresponding game steps are as follows: (1) The e-commerce platform determines the PBE level $\left(t_{p}\right)$. (2) The retailer decides the order quantity from e-commerce platform $\left(q_{p}\right)$ and from other channels $\left(q_{s}\right)$.

Because the platform is the leader in the game, the second stage of the game is first calculated. From the formula (1), we can get the optimal decisions in Proposition 2.

Proposition 2. For the DD scenario, the equilibrium solutions are as follows:

(1) The PBE level is $t_{p}^{D D *}=\theta \gamma\left(u+w_{s}-\lambda c_{f}\right) /(2 k(\beta+1))$

(2) The equilibrium order quantities from the platform and supplier are

$$
\begin{aligned}
& q_{p}^{\mathrm{DD} *}=\frac{\left[(1-\beta)\left(a-w_{s}+\theta \gamma K_{2}\left(u+w_{s}-\lambda c_{f}\right)\right)-u\right]}{2\left(1-\beta^{2}\right)}, \\
& q_{s}^{\mathrm{DD} *}=\frac{\left[(1-\beta)\left(a-w_{s}+\theta \gamma K_{2}\left(u+w_{s}-\lambda c_{f}\right)\right)+\beta u\right]}{2\left(1-\beta^{2}\right)},
\end{aligned}
$$

respectively, where $K_{2}=\theta \gamma /(2 k(\beta+1))$.

Corollary 2. The monotonicity of the equilibrium solutions is $q_{p}^{D D *}, q_{s}^{D D *}$, and $t_{p}^{D D *}$ all increase with $\gamma$ and decrease with $c_{f}, \beta$, and $k$. 
Different from the CD scenario, the greater the $c_{f}$, the less the product quantity ordered by retailer from e-commerce platform and the lower the empowerment level in the DD scenario; the reason is that e-commerce platform and retailer are chasing their own profits, and retailer does not consider the loss of e-commerce platform and orders more products from other channels with lower wholesale price and quality. Similarly, e-commerce platform reduces the invest in PBE to reduce the costs. As the $t_{p}$ decreases, the product price of e-commerce platform decreases; thus, the retailer's order quantity from supplier of other channels also reduces.

4.3. CS Scenario. In the scenario, e-commerce platform adopts empowerment cost sharing contract on the basis of DD scenario. Similar to the literatures of Ghosh et al. [67] and Zha et al. [68], we use $\mu(0 \leq \mu \leq 1)$ to represent the cost sharing ratio of retailer.

The corresponding game steps are as follows: (1) The brand empowerment cost sharing contract with retailer's sharing ratio $(\mu)$ is provided by e-commerce platform; (2) the e-commerce platform decides the PBE level $\left(t_{p}\right)$ and the unit wholesale price $\left(w_{s}\right)$; and (3) the retailer, respectively, decides the product quantity from e-commerce platform $\left(q_{p}\right)$ and supplier of other channel $\left(q_{s}\right)$.

Under the CS scenario, the platform's profit function is

$$
\Pi_{p}^{\mathrm{CS}}=w_{p} q_{p}-\frac{k}{2}(1-\mu) t_{p}^{2}-\lambda q_{s} c_{f} .
$$

The retailer's profit function is

$$
\Pi_{R}^{\mathrm{CS}}=\left(p_{p}-w_{p}\right) q_{p}-\frac{k}{2} \mu t_{p}^{2}+\left(p_{s}-w_{s}\right) q_{s} .
$$

According to the decision-making order, we still use the reverse induction method to solve the model, and the following conclusions can be drawn.

Proposition 3. For the CS scenario, the equilibrium solutions are as follows:

(1) The PBE level is $t_{p}^{C S *}=\theta \gamma\left(2 a-w_{s}-\lambda c_{f}\right) / 2 K_{1}$;

(2) The equilibrium product quantities from the e-commerce platform and other channels are

$$
\begin{aligned}
& q_{p}^{\mathrm{CS} *}=\frac{2 k(1+\beta)\left[(1-\beta)\left(a-w_{s}\right)-u\right]+\theta^{2} \gamma^{2}\left[2 u+(1-\beta)\left(w_{s}-\lambda c_{f}\right)\right]}{4 K_{1}\left(1-\beta^{2}\right)}, \\
& q_{s}^{\mathrm{CS} *}=\frac{2 k(1+\beta)\left[(1-\beta)\left(a-w_{s}\right)+u \beta\right]-\theta^{2} \gamma^{2}\left[(\beta-1)\left(w_{s}-\lambda c_{f}\right)+2 u \beta\right]}{4 K_{1}\left(1-\beta^{2}\right)} .
\end{aligned}
$$

(3) The empowerment cost sharing ratio of retailer is

$$
\mu^{\mathrm{CS} *}=\frac{\theta^{2} \gamma^{2}\left(u+w_{s}-\lambda c_{f}\right)+k(1+\beta)\left(2 a-u-2 w_{s}\right)}{k(1+\beta)\left(2 a-w_{s}-\lambda c_{f}\right)} \text {. }
$$

Corollary 3. The monotonicity of the equilibrium solutions is as follows:

(1) $q_{p}^{C S *}, q_{s}^{C S *}$, and $t_{p}^{C S *}$ decrease with $c_{f} ; \mu^{C S *}$ increases with $c_{f}$

(2) $q_{p}^{C S *}, q_{s}^{C S *}, t_{p}^{C S *}$, and $\mu^{C S *}$ increase with $\gamma$ and decreases with $\beta$ and $k$

Corollary 3 illustrates that with the increase of $c_{f}$, the empowerment cost sharing ratio will increase. In the case of other conditions unchanged, the e-commerce platform will increase the cost sharing ratio with retailer to reduce its own costs.

In addition, $\mu^{\mathrm{CS} *}$ increase with $\gamma$, the increase of $\mu^{\mathrm{CS} *}$ inspires e-commerce platform to invest more in PBE; then, the price will be higher and profits of e-commerce platform and retailer will both increase. Moreover, $\mu^{\mathrm{CS} *}$ decrease with $k$. Under the other conditions unchanged, the e-commerce platform will reduce the PBE level with the $k$ increase and the price will be lower, while the retailer's profit decreases with the increase in cost sharing ratio and retailer will order more products from supplier of other channels in order to increase profit, which leads to a greater loss of goodwill suffered by e-commerce platform, so platform has to lessen the $\mu^{\mathrm{CS} *}$ to reduce losses. Corollary 3 also shows that $\mu^{\mathrm{CS} *}$ decrease with $\beta$, the reason is that the increase in $\beta$ leads to the decrease in product price, and retailer will order more products with lower wholesale price from other channels to ensure its own profits, and e-commerce platform has to decrease cost sharing ratio in order to encourage retailer to order more products from it.

4.4. QC Scenario. In the scenario, e-commerce platform offers minimum order quantity contract to retailer on the basis of DD scenario. We assume that e-commerce platform takes incentive and punishment measures for retailer's order behaviors [57]. When $q_{p}>T$, the platform rewards $\tau\left(q_{p}-\right.$ $T$ ) to retailer's overfulfilled order. When $q_{p}<T$, the platform punishes $\tau\left(T-q_{p}\right)$ to the retailer for incomplete order, where $\tau$ is the reward and punishment coefficient, and $0<\tau<1, T$ is the reward and punishment standard that is set in advance as sales target in the contract between e-commerce platform and retailer.

Under the QC scenario, the profit of platform is written as follows: 


$$
\Pi_{P}^{\mathrm{QC}}=w_{p} q_{p}-\frac{k}{2} t_{p}^{2}-\lambda q_{s} c_{f}-\tau\left(q_{p}-T\right) .
$$

The retailer's profit function is given by

$$
\Pi_{R}^{\mathrm{QC}}=\left(p_{p}-w_{p}\right) q_{p}+\left(p_{s}-w_{s}\right) q_{s}+\tau\left(q_{p}-T\right) .
$$

Proposition 4. For the QC scenario, the equilibrium solutions are as follows:

(1) The PBE level is $t_{p}^{Q C *}=\theta \gamma\left(2 a-w_{s}-\lambda c_{f}\right) / 2 K_{1}$.

(2) The equilibrium order quantities from the platform and supplier are

$$
\begin{aligned}
& q_{p}^{\mathrm{QC} *}=\frac{\left[2 a k(1-\beta)+\left(w_{s}+\lambda c_{f}\right)\left(2 k \beta-\theta^{2} \gamma^{2}\right)\right]}{4 K_{1}(1-\beta)}, \\
& q_{s}^{\mathrm{QC} *}=\frac{\left[2 a k(1-\beta)-\lambda c_{f}\left(2 k \beta^{2}-\theta^{2} \gamma^{2}(2 \beta-1)\right)-w_{s}\left(2 k-\theta^{2} \gamma^{2}\right)\right]}{4 K_{1}(1-\beta)} .
\end{aligned}
$$

(3) The coefficient of reward and punishment is

$$
\tau^{\mathrm{QC} *}=u+w_{s}+\beta \lambda c_{f} .
$$

Corollary 4. The monotonicity of the equilibrium solutions is as follows:

(1) $q_{s}^{\mathrm{QC} *}$ and $t_{p}^{\mathrm{QC} *}$ decrease with $c_{f} ; q_{p}^{\mathrm{QC} *}$ increases with $c_{f}$

(2) $q_{p}^{Q C *}, q_{s}^{Q C *}$, and $t_{p}^{Q C *}$ increase with $\gamma$ and decrease with $\beta$ and $k$

Corollary 4 shows that $q_{p}^{\mathrm{QC} *}$ increases with $c_{f}$ and $\gamma$ but decreases with $\beta$ and $k$, which is the same as CD scenario; the greater the $c_{f}$, the more the products are ordered from platform. With the $c_{f}$ increase, the reward and punishment coefficient $\tau$ also increases, which encourages retailer to order products from platform, and the risk of goodwill loss to the platform also reduces.

\section{Comparative Analysis of Different Supply Chain Scenarios}

In different scenarios, the retailer's order decisions and the e-commerce platform's PBE level decision are key decision variables for the supply chain. In this section, we focus on analyzing the relationships between these decision variables and the impact of these variables on the profits of supply chain members.

5.1. Decision Comparisons. To get more insights on decisionmaking of supply chain members under the different scenarios, we compare the important variables in the following.

Corollary 5. The optimal PBE levels under different scenarios satisfy the relationship as $t_{p}^{Q C *}=t_{p}^{C S *}=t_{p}^{C D *}>t_{p}^{D D *}$.

Corollary 5 shows that the optimal PBE level of e-commerce platform can reach the level of CD scenario, and it is greater than that under the DD scenario through the coordination of CS and QC. It means that by implementing cost sharing contract and minimum order quantity contract, e-commerce platform can better exert its PBE level and retailer can also get much support from the platform.

Corollary 6. The optimal decisions about products quantities ordered by retailer from e-commerce platform under different scenarios satisfy the relationship as $q_{p}^{C D *}=q_{P}^{Q C *}>$ $q_{P}^{C S *}>q_{P}^{D D *}$.

Corollary 6 reveals that optimal product quantities ordered by retailer from platform under CS and QC scenarios are greater than that under DD scenario. Moreover, under the QC scenario, the optimal product quantity is the same as that under the $\mathrm{CD}$ scenario and is greater than that under the CS scenario. Therefore, the e-commerce platform can effectively encourage retailer to order more products from itself through CS and QC, which guarantees product quality sold by retailer to a certain extent, especially QC is more helpful to achieve the goal.

Corollary 7. The optimal product quantity ordered by retailer from other channels under different scenarios satisfy the following:

(1) When $0<\gamma^{2}<\left(\bar{\varphi} / \theta^{2}\right)$, we have $q_{s}^{C S *}>q_{s}^{D D *}$ $>q_{s}^{\mathrm{QC} *}>q_{s}^{C D *}$

(2) When $\left(\bar{\varphi} / \theta^{2}\right)<\gamma^{2}<\left(k(\beta+1) / \theta^{2}\right)$, we have $q_{s}^{C S *}$ $>q_{s}^{\mathrm{QC} *}>q_{s}^{D D *}>q_{s}^{\mathrm{CD} *}$

From Corollary 7, we find that CS always encourages retailer to order more products from other channels whether the impact of price on goodwill is high or low. The reason is that retailer has to share part of the cost of PBE under the CS scenario. In order to make up for the decline of its own profit, retailer order more products from supplier with lower wholesale prices. In addition, the products ordered from supplier in the QC scenario are less than that in the DD scenario when $\gamma$ is small; otherwise, the situation is the opposite. This is because that when goodwill has little impact on the price, the price of products ordered from other channels is lower so that the retailer's profit gained from other channels is relatively low. With the incentive of the reward and punishment mechanism, retailer is more inclined to order 
products from the platform. While when goodwill has a greater impact on the price, the price of products ordered from other channels is higher, which increase the profit of retailer and retailer prefer to order products from other channels.

Both Corollaries 6 and 7 illustrate that QC can effectively motivate the retailer to order more products from platform, especially, it can reduce the product quantity ordered from other channels when goodwill has less of an effect on price, which is more effective than CS in reducing channel conflicts and ensuring product quality.

Corollary 8. The optimal ratio of product quantities ordered by retailer from e-commerce platform to total quantity under different scenarios satisfy the relationship as $r_{p}^{C D *}>r_{p}^{Q C *}>r_{p}^{C S *}>r_{p}^{D D *}$.

Through Corollary 8, we find that QC and CS can effectively encourage retailer to increase the proportion of product quantity ordered from the platform and reduce that from other channels. Especially, the ratio under the QC scenario is greater than that under CS and DD scenarios.

Thus, e-commerce platform can effectively stimulate retailer's order ratios from itself by adopting minimum order quantity contract. Although Corollary 7 shows that QC will increase the product quantity from other channels when $\left(\bar{\varphi} / \theta^{2}\right)<\gamma^{2}<\left(k(\beta+1) / \theta^{2}\right)$, the retailer's order ratio from the platform is greater than that under the CS and DD scenarios. That is to say, the platform can stimulate the retailer's quantity order from itself by providing QC, which possibly reduce the loss of goodwill of the platform caused by counterfeit products.

What's more, although Corollaries 6 and 7 show that products ordered from other channels in the CS scenario is more than that in the DD scenario, the CS also increases product quantity ordered from the platform. It can be drawn from Corollary 8 that the ratio of product quantity from platform in CS scenario is higher than that of DD scenario, which means CS contract still has a positive effect on encouraging retailer to order more products from the platform on the whole.

5.2. Comparison of Profits. In order to better analyze the changes in the profits of e-commerce platform and retailer under different scenarios, we assumed that $w_{s}=0$. That is to say, the wholesale price of products ordered from other channels is very low, which closes to zero.

Corollary 9. Comparing the profit of platform and retailer under CS scenario and DD scenario, we have

(1) $\Pi_{P}^{C S *}>\Pi_{P}^{D D *}$
(2) $\Pi_{R}^{C S *}>\Pi_{R}^{D D *}$

Obviously, the empowerment cost sharing contract can alleviate the channel conflicts between e-commerce platform and retailer and realize the Pareto improvement of their profits compared with DD scenario.
Corollary 10. The optimal total profit of platform and retailer under different scenarios satisfies the relationship as $\Pi_{C}^{C D *}>\Pi_{C}^{Q C *}>\Pi_{C}^{C S *}>\Pi_{C}^{D D *}$.

Both Corollaries 8 and 10 show that compared with CS, QC can not only better motivate retailer to order more products from platform but also improve the profits of platform and retailer.

Theorem 1. If platform provides an incentive mechanism as $\tau(Q-T)$ in a nonvertically integrated mixed channel scenario, where $\tau=w_{p}+\beta \lambda c_{f}$. There is $T_{1}, T_{2}, T_{3}, T_{4}, T_{5}, T_{6}$ and $T_{4}>T_{3}>T_{2}>T_{1}, T_{6}>T_{5}$ :

(1) When $T \in\left(T_{1}, T_{2}\right]$, after coordination of QC, the retailer's profit is greater than that under the $D D$ scenario, but e-commerce platform's profit is opposite

(2) When $T \in\left(T_{2}, T_{3}\right)$, both e-commerce platform and retailer's profits are greater than that under the $D D$ scenario

(3) When $T \in\left[T_{3}, T_{4}\right)$, e-commerce platform's profit is greater than that under the DD scenario, while retailer's profit is the opposite

(4) When $T \in\left(T_{5}, T_{6}\right)$, both the profits of e-commerce platform and retailer are greater than that under the CS scenario

The first three illustrate that the QC can effectively reduce vertical channel conflicts of supply chain with PBE in a suitable range, and Theorem 1 (4) shows that the QC has a better effect than the CS; thus, e-commerce platform can choose incentive and punishment standard acceptable to itself and retailer according to the actual situation, so that they can achieve a win-win situation.

Corollary 11. When $T=0, \Pi_{P}^{Q C *}<0$, the linear rebate with minimum order quantity cannot achieve the coordination of supply chain.

Corollary 11 demonstrates that the minimum order quantity contract can degenerate into a linear rebate mechanism when $T=0$, and retailer will receive rebate $\tau>0$ when $q_{p}^{\mathrm{QC}}>0$ of each unit product. In order to encourage retailer to order the same product quantity from e-commerce platform as CD scenario, the rebate provided by the platform needs to satisfy $\tau=u+w_{s}+\beta \lambda c_{f}$, which makes e-commerce platform's profit negative. Therefore, the linear rebate mechanism does not coordinate the supply chain.

\section{Numerical Simulation}

This part further analyzes the impact of key variables on the supply chain. Especially, we assume that $w_{s} \neq 0$, and consider the numerical analysis of the sensitivity of the coefficients and variables. From the assumptions and practical situations, the basic parameter values are assigned as follows: $a=1, \beta=0.4, \theta=0.2, \gamma=0.15, \lambda=0.2, c_{f}=0.15, u=0.2$, $k=0.005, w_{s}=0.2$. 


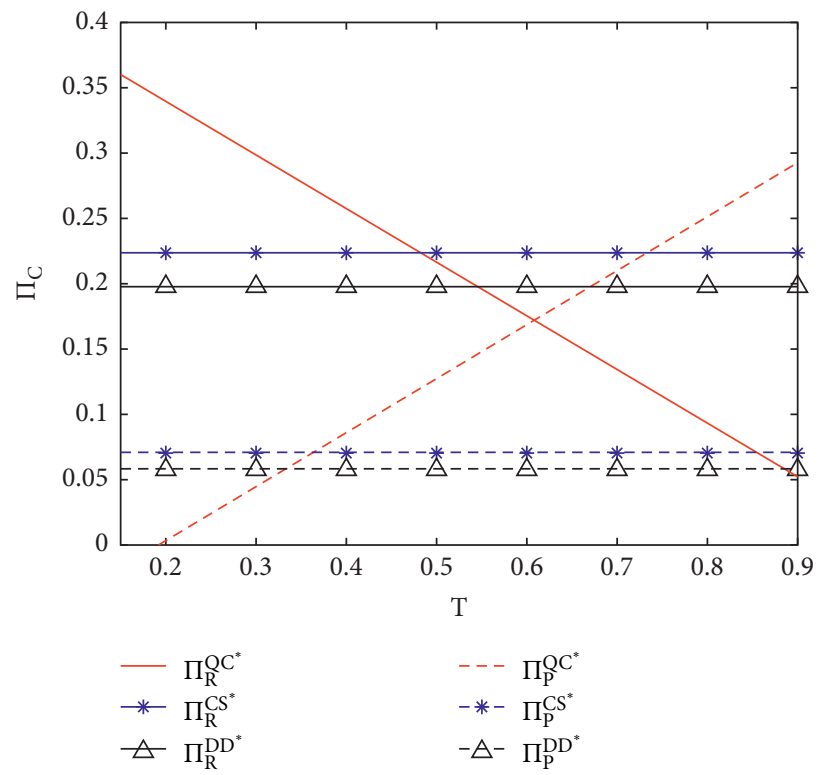

FIgURE 2: Impact of $T$ on e-commerce platform and retailer's profits.

6.1. Impact of Reward and Punishment Standard $T$ on the Profits of Platform and Retailer. Figure 2 shows the results of profit comparison under different scenarios. We find that both platform and retailer's profit under CS scenario are always higher than that under DD scenario. However, the situation under QC scenario is more complicated. When $T$ is at $(0.19$, 0.33 ), the platform's profit is less than that under CS and DD scenarios, whereas the retailer's profit is highest of three scenarios, that is, the platform's profit is damaged and QC is beneficial to the retailer; as $T$ increases in $(0.33,0.37)$, retailer's profit is still the highest under all three different scenarios; the platform's profit is higher than that under DD scenario but lower than that under CS scenario. As $T$ increases in $(0.37$, 0.48 ), both the platform and retailer have the highest profit under the three scenarios and QC is the best choice for them. When $T$ is at $(0.48,0.55)$, the platform's profit increases and it is the highest of the three scenarios, whereas retailer's profit decreases and it is greater than that under DD scenario but less than CS scenario, and QC is the best choice for platform. The reason is that retailer order expensive products from platform because of high standard, and platform's profit will be higher, whereas the retailer's profit will be lower with the increase of $T$.

In summary, platform and retailer have always embraced CS because it increases their profits. When $T$ is small, the platform is not willing to provide QC for that the expected profit it brings will be lower than that under DD scenario. Figure 2 verifies Theorem 1 that only when $T$ is within the appropriate range can QC be accepted by both retailer and platform, and there is Pareto improvements of platform and retailer's profits. For example, Alibaba requires that retailers must order more than $30 \%$ of products from Ali Retail Link every month, if the amount of money reaches 5000 yuan, the retailers can get a reward, which can greatly encourage them to order more products from platform, and the profits of both sides can be improved. Otherwise, QC will reduce the profit of one party and the channel conflicts cannot be alleviated.
6.2. The Impact of Reaction Coefficient of Price to Goodwill $\gamma$ on the Total Profit of Platform and Retailer. It can be seen that as $\gamma$ increases, the price of product increases and retailer will order more products from e-commerce platform, which increases the profits of both. However, due to the existence of channel conflicts, the profit growth is slow, and the profits under DD scenario are always the lowest.

Figure 3 shows that as $\gamma$ increases, the effect of the two contracts on channel conflicts gradually increases; especially, QC's effect is always better. When $\gamma$ is small, the effect of CS is not obvious, and it gradually increases only when $\gamma$ is large. What's more, the gap between the two contracts' improvement effects gradually becomes smaller as $\gamma$ increases. Therefore, for the platform, it is necessary to choose contract based on the degree of influence of the products it provides on the goodwill, minimum order quantity contract can be selected for products whose prices are less affected by goodwill, such as JD Convenience Store mainly deals in snacks and daily necessities, whose price is less affected by goodwill. With the incentive of minimum order quantity contract, retailers are more willing to order products from the platform in order to increase profits, and channel conflicts have been effectively reduced; otherwise, both QC and CS contracts can be selected. However, by comparing Figures 2 and 3, we can find that QC is not always the best choice for the platform, if the reward and punishment mechanism is not set properly, platform's profit in QC will decline, which is a problem it needs to be aware of.

6.3. Impact of Product Substitutability $\beta$ on the Total Profit of Platform and Retailer. Figure 4 shows that with the increase of $\beta$, not only is profit decreases but also is their improvement on channel conflicts, especially the downward trend of QC slow down as the competition intensifies because the incentive and punishment coefficient set by the 


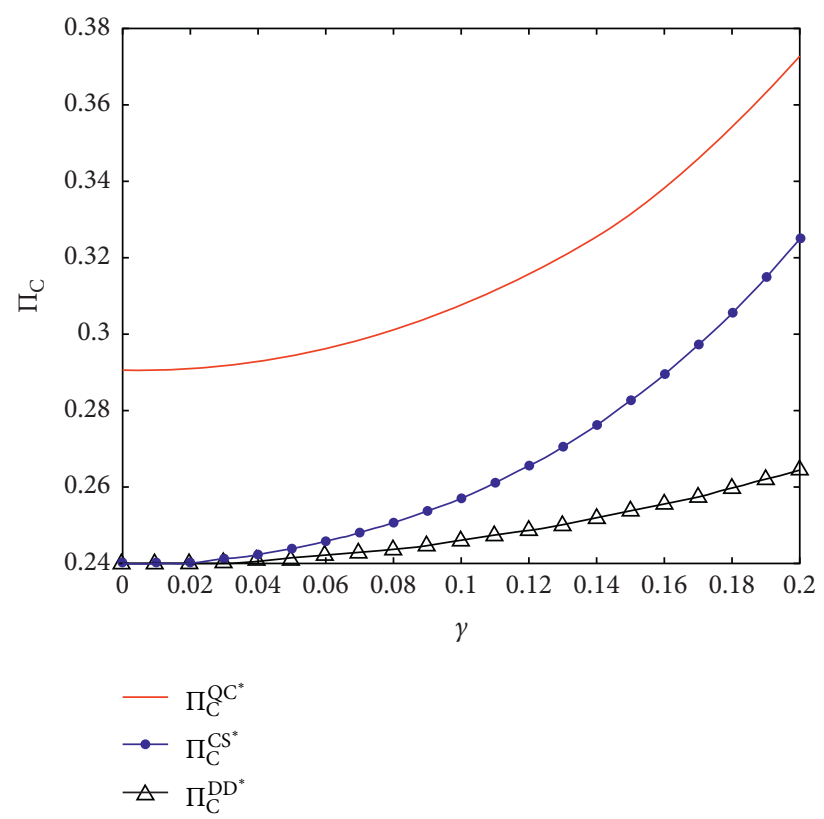

Figure 3: Impact of $\gamma$ on the total profit of platform and retailer.

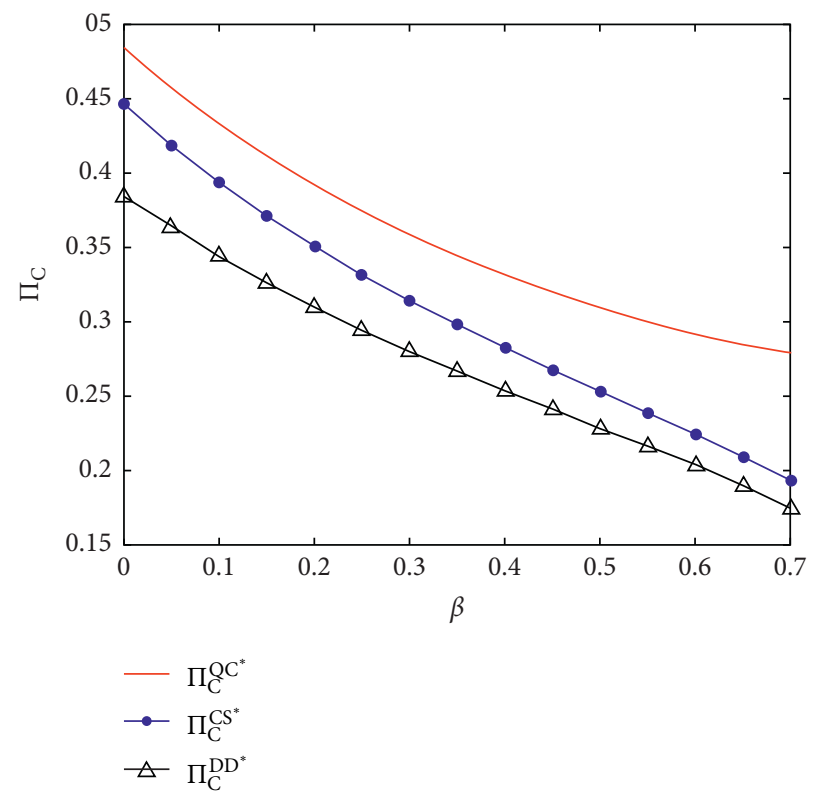

FIGURE 4: Impact of $\beta$ on the profit of platform and retailer.

platform will increase, which encourages retailer to increase product quantity ordered from the platform, and the goodwill loss suffered by it will gradually reduce. With the intensification of product competition, QC's effect in improving profits is more obvious.

In order to improve the features and differences of products, e-commerce platform often takes product differentiation strategy, such as improve the product quality and style to reduce channel conflicts. For example, JD.com has established differentiated competitive advantage by making its own products to ensure their quality and cost performance. However, as can be seen from Figure 4, because the wholesale price of the products provided by the platform is higher, retailers will order cheaper but lower quality products from other suppliers in order to maximize their profits. Therefore, the platform will still suffer the loss of goodwill due to the potential quality problems of products. Thus, for commodities and other competitive products, e-commerce platform can adopt QC and CS to coordinate, while for some valuable products, e-commerce platform can reduce channel conflicts through QC. 


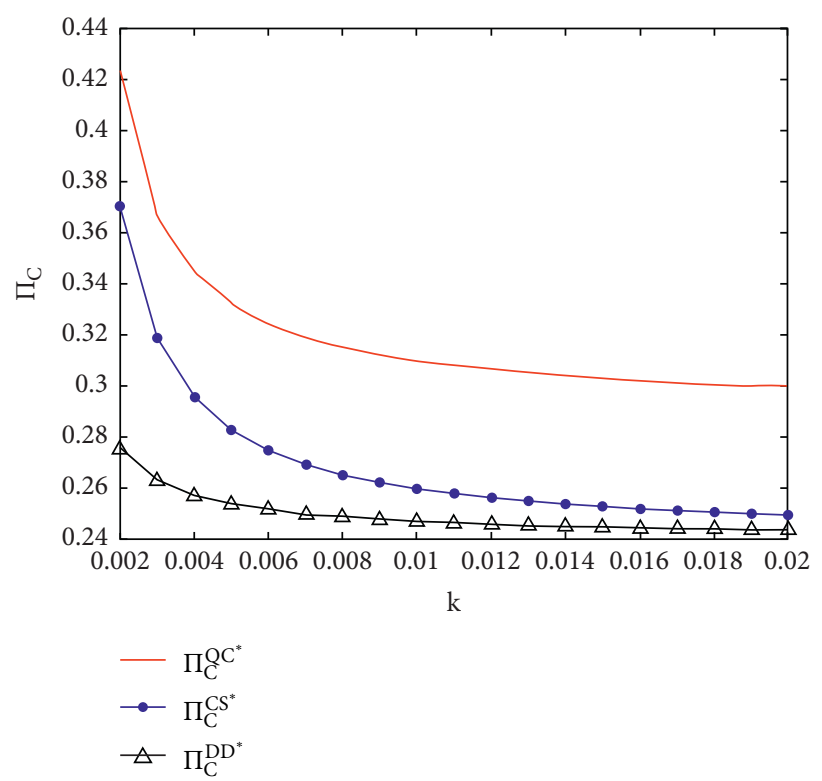

Figure 5: Impact of $k$ on the profit of platform and retailer.

6.4. Impact of Empowerment Cost Coefficient $k$ on the Total Profit of Platform and Retailer. Figure 5 indicates that the increase of $k$ has a negative impact on the total profit of platform and retailer under three different scenarios, the reason is that platform will increase products' wholesale price because of high empowerment cost; thus, retailer will order more products from supplier to increase its profit, which may cause goodwill loss to platform. We find that the improvement effect of CS and QC both weaken with the increase in $k$ in a small range, whereas when $k$ increases in a large range, their decreasing trends gradually slow down. Especially, the improvement effect of QC is always better than that of CS in the part of analysis.

On the one hand, when the cost of PBE is high, the platform can use QC to reduce channel conflicts; otherwise, both CS and QC can be used. On the other hand, Figure 5 shows that the profit will increase rapidly as $k$ decreases. Thus, how to reduce the cost coefficient of PBE is an important issue for the platform to consider. For example, platform can use event marketing, personalized customization, and other ways to improve the efficiency of empowerment to reduce the cost of empowerment. Take JD Convenience Store as an example, with the help of JD.com, it became the design theme of a design competition and successfully publicized its brand and concept to the society; also, JD.com uses its advantages to help it optimize the consumption scene and make it more in line with the shopping habits of target customers, thus stimulating consumers' demand.

\section{Conclusion}

In this article, we construct a two-echelon supply chain model, explore how to mitigate vertical channel conflicts caused by retailer's "free-rider" behavior chasing short-term interests and inconsistent business goals between the two parties, and further study the coordination effect of cost sharing contract and minimum order quantity contract on vertical channel conflicts.

First, channel conflicts can reduce product quantity ordered by retailer from platform and lead to a loss of goodwill of platform. Secondly, both cost sharing contract and minimum order quantity contract can effectively reduce channel conflicts, and the effect of minimum order quantity contract is greater than that of cost sharing contract. Minimum order quantity contract can not only help e-commerce platform and retailer obtain more profits but also achieve the optimal PBE level and product quantity from platform under centralized decision scenario. Thirdly, e-commerce platform through differentiated product strategy can reduce the degree of competition between the two products and reduce vertical channel conflicts, but it cannot achieve the coordination of the supply chain, and platform still needs to design proper contract to improve the product quantity ordered from itself. Finally, with the increase in the degree of competition between the two products and the cost of $\mathrm{PBE}$, the improvement effect of empowerment cost sharing contract decreases, whereas the effect of minimum order quantity contract increase. 
However, with the increase in the reaction coefficient of prices on goodwill, the effect of those two contracts increases.

There are some directions for future research:

(1) We only consider the problem under the context of information symmetry; however, the information between platform and retailer is probably asymmetric in reality. Taking JD.com as an example, in order to better meet the market demand, retailers are allowed to order products from other channels; however, JD.com does not know the quality of these products. High-quality products will not affect the goodwill of the platform, while unqualified products may hurt the goodwill of the platform. Therefore, the study of asymmetric information about product quality is very useful to reduce channel conflict.

(2) This article studies the coordination strategy of channel conflicts under the determined demand, future research can explore channel conflicts under the uncertain demand, which is a classic problem that has always been studied in supply chain management. Also, as competition intensifies, the business environment is undergoing dynamic changes, and market demand is in an uncertain state, so it is necessary to study the problem of channel conflict under the uncertain demand.

(3) This article examines the single-period model; however, $\mathrm{PBE}$ is a continuous process and the platform will decide the level of PBE according to its own interests, market environment, and other specific circumstances. Therefore, the study of channel conflict in multiperiod dynamic environment can indicate the dynamic decision-making process of the platform.

\section{Appendix}

Proof of Proposition 1. First, from function (3), the firstorder partial derivative of $q_{s}, q_{p}$, and $t_{p}$ for $\Pi_{\mathrm{CD}}$ are as follows:

$$
\begin{gathered}
\frac{\partial \Pi_{\mathrm{CD}}}{\partial q_{p}}=a-2 q_{p}-2 q_{s} \beta+t_{p} \theta \gamma=0, \\
\frac{\partial \Pi_{\mathrm{CD}}}{\partial q_{s}}=a-2 q_{s}-c_{f} \lambda-2 q_{p} \beta+\theta t_{p} \gamma-w_{s}=0, \\
\frac{\partial \Pi_{\mathrm{CD}}}{\partial t_{p}}=q_{p} \gamma \theta-k t_{p}+q_{s} \gamma \theta=0 .
\end{gathered}
$$

Then, we continue to calculate partial derivative, and the results are as follows:

$$
\begin{aligned}
& \frac{\partial^{2} \Pi_{C}^{\mathrm{CD}}}{\partial q_{p}^{2}}=-2, \\
& \frac{\partial^{2} \Pi_{C}^{\mathrm{CD}}}{\partial q_{s}^{2}}=-2, \\
& \frac{\partial^{2} \Pi_{C}^{\mathrm{CD}}}{\partial t_{p}^{2}}=-k, \\
& \frac{\partial^{2} \Pi_{C}^{\mathrm{CD}}}{\partial q_{p} \partial q_{s}}=-2 \beta, \\
& \frac{\partial^{2} \Pi_{C}^{\mathrm{CD}}}{\partial q_{p} \partial t_{p}}=\theta \gamma, \\
& \frac{\partial^{2} \Pi_{C}^{\mathrm{CD}}}{\partial q_{s} \partial q_{p}}=-2 \beta, \\
& \frac{\partial^{2} \Pi_{C}^{\mathrm{CD}}}{\partial q_{s} \partial t_{p}}=\theta \gamma, \\
& \frac{\partial^{2} \Pi_{C}^{\mathrm{CD}}}{\partial t_{p} \partial q_{p}}=\theta \gamma, \\
& \frac{\partial^{2} \Pi_{C}^{\mathrm{CD}}}{\partial t_{p} \partial q_{s}}=\theta \gamma .
\end{aligned}
$$

When $k(\beta+1)-\theta^{2} \gamma^{2}>0$, the Hesse matrix on $\Pi_{\mathrm{CD}}$ is negative, so $\Pi_{\mathrm{CD}}$ can get the maximum under specific $q_{p}, q_{s}$, and $t_{p}$.

From the formulation (A.1)-(A.3), we get the equilibrium solution in the centralized scenario:

$$
\begin{gathered}
q_{p}^{\mathrm{CD} *}=\frac{2 a k(1-\beta)+\left(w_{s}+\lambda c_{f}\right)\left(2 k \beta-\theta^{2} \gamma^{2}\right)}{4(1-\beta) K_{1}}, \\
q_{s}^{\mathrm{CD} *}=\frac{2 a k(1-\beta)-\left(w_{s}+\lambda c_{f}\right)\left(2 k-\theta^{2} \gamma^{2}\right)}{4(1-\beta) K_{1}}, \\
t_{p}^{\mathrm{CD} *}=\frac{\theta \gamma\left(2 a-w_{s}-\lambda c_{f}\right)}{2 K_{1}} .
\end{gathered}
$$

According to $0 \leq t_{p} \leq 1$, we get $k(\beta+1)>\theta^{2} \gamma^{2}$, and $k \geq\left(\theta \gamma\left(2 a-w_{s}-\lambda c_{f}\right)+2 \theta^{2} \gamma^{2}\right) /(2(1+\beta))$.

Proof of Corollary 1. (1) From equation (A.5)-(A.7), the first-order partial derivatives of $c_{f}, \gamma, k$, and $\beta$ can be shown as follows: 


$$
\begin{aligned}
& \frac{\partial q_{p}^{\mathrm{CD} *}}{\partial c_{f}}=\frac{\lambda\left(2 k \beta-\theta^{2} \gamma^{2}\right)}{4(1-\beta) K_{1}^{2}}>0, \\
& \frac{\partial q_{s}^{\mathrm{CD} *}}{\partial c_{f}}=-\frac{\lambda\left(2 k \beta-\theta^{2} \gamma^{2}\right)}{4(1-\beta) K_{1}^{2}}<0, \\
& \frac{\partial t_{p}^{\mathrm{CD} *}}{\partial c_{f}}=-\frac{\theta \lambda \gamma}{2 K_{1}}<0, \\
& \frac{\partial q_{p}^{\mathrm{CD} *}}{\partial \gamma}=\frac{\theta^{2} k \gamma\left(2 a-w_{s}-\lambda c_{f}\right)}{2 K_{1}^{2}}>0, \\
& \frac{\partial t_{p}^{\mathrm{CD} *}}{\partial \gamma}=\frac{\theta\left(k+\theta^{2} \gamma^{2}+k \beta\right)\left(2 a-w_{s}-\lambda c_{f}\right)}{2 K_{1}^{2}}>0 ; \\
& \frac{\partial q_{p}^{\mathrm{CD} *}}{\partial k}=-\frac{\theta^{2} \gamma^{2}\left(2 a-w_{s}-\lambda c_{f}\right)}{4 K_{1}^{2}}<0, \\
& \frac{\partial q_{s}^{\mathrm{CD} *}}{\partial k}=-\frac{\theta^{2} \gamma^{2}\left(2 a-w_{s}-\lambda c_{f}\right)}{4 K_{1}^{2}}<0, \\
& \frac{\partial q_{s}^{\mathrm{CD} *}}{\partial \gamma}=\frac{\theta^{2} k \gamma\left(2 a-w_{s}-\lambda c_{f}\right)}{2 K_{1}^{2}}>0, \\
& \frac{\partial t_{p}^{\mathrm{CD} *}}{\partial k}=-\frac{\theta \gamma(\beta+1)\left(2 a-w_{s}-\lambda c_{f}\right)}{\partial \beta}<0 ; \\
& \frac{\partial q_{1}^{2} *}{2 \beta}=-\frac{2 a k^{2}(1-\beta)^{2}-\left(w_{s}+\lambda c_{f}\right)\left[\theta^{2} \gamma^{2}\left(-2 k+\theta^{2} \gamma^{2}-2 k \beta\right)+2 k^{2}\left(\beta^{2}+1\right)\right]}{4(1-\beta)^{2} K_{1}^{2}}<0 .
\end{aligned}
$$

The reason is that $2 a k^{2}(1-\beta)^{2}-\left(w_{s}+\lambda c_{f}\right)\left(\theta^{4} \gamma^{4}+2 k^{2} \beta^{2}+\right.$ $\left.2 k^{2}-2 k \theta^{2} \gamma^{2}-2 k \beta \theta^{2} \gamma^{2}\right)>\left(k-\theta^{2} \gamma^{2}+k \beta\right)\left(w_{s}+\lambda c_{f}\right)>0$ due to $2 a>w_{s}+\lambda c_{f}$.

$$
\begin{aligned}
& \frac{\partial q_{s}^{\mathrm{CD} *}}{\partial \beta}=-\frac{\left(w_{s}+\lambda c_{f}\right)\left(\theta^{2} \gamma^{2}+2 k^{2} \beta^{2}+2 k^{2}-2 k \theta^{2} \gamma^{2}-2 k \beta \theta^{2} \gamma^{2}\right)}{4 K_{1}^{2}(1-\beta)^{2}}<0, \\
& \frac{\partial t_{p}^{\mathrm{CD} *}}{\partial \beta}=-\frac{k \theta \gamma\left(w_{s}+\lambda c_{f}\right)}{2 K_{1}^{2}}<0 .
\end{aligned}
$$

Proof of Proposition 2. From equation (1), the first-order partial derivatives of $\Pi_{R}$ to $q_{p}, q_{s}$, we get 


$$
\begin{aligned}
q_{p}^{\mathrm{DD}}\left(t_{p}\right) & =\frac{\left(a-w_{s}+\theta t_{p} \gamma\right)(1-\beta)-u}{2\left(1-\beta^{2}\right)}, \\
q_{s}^{\mathrm{DD}}\left(t_{p}\right) & =\frac{\left(a-w_{s}+\theta t_{p} \gamma\right)(1-\beta)+u \beta}{2\left(1-\beta^{2}\right)} .
\end{aligned}
$$

Taking equation (A.10) and (A.11) into $\Pi_{p}^{\mathrm{DD}}$ and calculating its first-order partial derivative, we get ( $\left.\partial \Pi_{p}^{\mathrm{DD}} / \partial t_{p}\right)=\left(\left(-2 k t_{p}(\beta+1)+\theta \gamma\right.\right.$ $\left.\left.\left(u+w_{s}-\lambda c_{f}\right)\right) / 2(\beta+1)\right)$.

Let it equal to 0 , we obtain the equilibrium solution,

$$
t_{p}^{\mathrm{DD}^{*}}=\frac{\theta \gamma\left(u+w_{s}-\lambda c_{f}\right)}{2 k(\beta+1)}
$$

In order to simplify the formula, let $K_{2}=\theta \gamma /(2 k(\beta+1))$, thus,

$$
t_{p}^{\mathrm{DD}^{*}}=K_{2}\left(u+w_{s}-\lambda c_{f}\right) .
$$

Taking (A.13) into formula (1), we get

$$
q_{p}^{\mathrm{DD} *}=\frac{(1-\beta)\left(a-w_{s}+\theta \gamma K_{2}\left(u+w_{s}-\lambda c_{f}\right)\right)-u}{2\left(1-\beta^{2}\right)},
$$

$$
q_{s}^{\mathrm{DD} *}=\frac{(1-\beta)\left[a-w_{s}+\theta \gamma K_{2}\left(u+w_{s}-\lambda c_{f}\right)\right]+\beta u}{2\left(1-\beta^{2}\right)}
$$

and $(1-\beta)\left[a-w_{s}+\theta \gamma K_{2}\left(u+w_{s}-\lambda c_{f}\right)\right] \geq u$.

Proof of Corollary 2. From equation (A.13)-(A.15), the firstorder partial derivatives of $\gamma, c_{f}, \beta$, and $k$ can be are as follows:

$$
\begin{aligned}
& \frac{\partial q_{p}^{\mathrm{DD} *}}{\partial \gamma}=\frac{\theta^{2} \gamma\left(u+w_{s}-\lambda c_{f}\right)}{2 k(\beta+1)^{2}}>0, \\
& \frac{\partial q_{s}^{\mathrm{DD} *}}{\partial \gamma}=\frac{\theta^{2} \gamma\left(u+w_{s}-\lambda c_{f}\right)}{2 k(\beta+1)^{2}}>0, \\
& \frac{\partial t_{p}^{\mathrm{DD} *}}{\partial \gamma}=\frac{\theta\left(u+w_{s}-\lambda c_{f}\right)}{2 k(\beta+1)}>0 ; \\
& \frac{\partial q_{p}^{\mathrm{DD} *}}{\partial c_{f}}=-\frac{\theta^{2} \lambda \gamma^{2}}{4 k(\beta+1)^{2}}<0, \\
& \frac{\partial t_{p}^{\mathrm{DD} *}}{\partial c_{f}}=-\frac{\theta \lambda \gamma}{2 k(\beta+1)}<0, \\
& \frac{\partial q_{s}^{\mathrm{DD} *}}{\partial c_{f}}=-\frac{\theta^{2} \gamma^{2} \lambda}{4 k(\beta+1)^{2}}<0 ; \\
& \frac{\partial q_{p}^{\mathrm{DD} *}}{\partial k}=-\frac{\theta^{2} \gamma^{2}\left(u+w_{s}-\lambda c_{f}\right)}{4 k^{2}(\beta+1)^{2}}<0, \\
& \frac{\partial q_{s}^{\mathrm{DD} *}}{\partial k}=-\frac{\theta^{2} \gamma^{2}\left(u+w_{s}-\lambda c_{f}\right)}{k^{2}(\beta+1)^{2}}<0, \\
& \frac{\partial t_{p}^{\mathrm{DD} *}}{\partial k}=-\frac{\theta \gamma\left(u+w_{s}-\lambda c_{f}\right)}{2 k^{2}(\beta+1)}<0 ; \\
& \left.\frac{\partial q_{p}^{\mathrm{DD} *}}{\partial \beta}=-\frac{(\beta-1)^{2}\left(a k(\beta+1)-k w_{s}(\beta+1)+\theta^{2} \gamma^{2}\left(u+w_{s}-\lambda c_{f}\right)\right)+2 k u \beta(\beta+1)}{\partial \beta}<0,1 \beta-1\right)^{2}(\beta+1)^{3} \\
& \frac{\partial q_{s}^{\mathrm{DD} *}}{\partial \beta}=
\end{aligned}
$$


Let $f(k)=(\beta-1)^{2}\left(k(\beta+1) \quad\left(a-w_{s}\right)+\theta^{2} \gamma^{2} \quad(u\right.$ $\left.\left.+w_{s}-\lambda c_{f}\right)\right)-k u(\beta+1)\left(\beta^{2}+1\right), f^{\prime}(k)=(\beta+1)\left((\beta-1)^{2}\right.$ $\left.\left(a-w_{s}\right)-u\left(\beta^{2}-1\right)\right)>0$, we have $f(k)>0$ because $k>0$ and $f(k=0)=\theta^{2} \gamma^{2}(\beta-1)^{2}\left(u+w_{s}-\lambda c_{f}\right)>0$; thus, $\left(\partial q_{s}^{D} D *\right.$ $/ \partial \beta)=-\left(\left((\beta-1)^{2} \quad\left(k(\beta+1)\left(a-w_{s}\right)+\theta^{2} \gamma^{2}\left(u+w_{s}\right.\right.\right.\right.$ $\left.\left.\left.\left.-\lambda c_{f}\right)\right)-k u(\beta+1)\left(\beta^{2}+1\right)\right) /\left(2 k(\beta-1)^{2}(\beta+1)^{3}\right)\right)<0$.

Proof of Proposition 3. From equation (6), the first-order partial derivatives of $q_{p}^{\mathrm{CS}}$ and $q_{s}^{\mathrm{CS}}$ can be shown as

$$
\begin{gathered}
\frac{\partial \Pi_{R}^{\mathrm{CS}}}{\partial q_{p}}=a-2 q_{p}-u-w_{s}-2 \beta q_{s}+\theta \gamma t_{p}=0, \\
\frac{\partial \Pi_{R}^{\mathrm{CS}}}{\partial q_{s}}=a-2 q_{s}-w_{s}-2 \beta q_{p}+\theta \gamma t_{p}=0 .
\end{gathered}
$$

From the formula (A.17) and (A.18), we get

$$
\begin{aligned}
& q_{p}^{\mathrm{CS}}=\frac{-a+u+w_{s}+a \beta-\beta w_{s}-\theta \gamma t_{p}+\theta \beta \gamma t_{p}}{2\left(\beta^{2}-1\right)}, \\
& q_{s}^{\mathrm{CS}}=\frac{a \beta-a+u+\theta \beta \gamma t_{p}-\beta w_{s}-\beta u-\theta \gamma t_{p}}{2\left(\beta^{2}-1\right)} .
\end{aligned}
$$

Taking (A.19) into equation 5 and calculating the partial derivatives of $t_{p}$, we have

$$
t_{p}^{\mathrm{CS}}=\frac{\theta \gamma\left(u+w_{s}-\lambda c_{f}\right)}{-2 k(\mu-1)(\beta+1)} .
$$

Similarly, taking (A.19) and (A.21) into $\Pi_{C}$ and calculating the partial derivatives of $u$, we have

$$
\mu^{\mathrm{CS}^{*}}=\frac{\theta^{2} \gamma^{2}\left(u+w_{s}-\lambda c_{f}\right)+k(\beta+1)\left(2 a-u-2 w_{s}\right)}{k(\beta+1)\left(2 a-w_{s}-\lambda c_{f}\right)},
$$

where $\mu^{\mathrm{CS}^{*}} \in[0,1]$.

Taking (A.22) into (A.19) and (A.21), we get

$$
\begin{gathered}
t_{p}^{\mathrm{CS} *}=\frac{\theta \gamma\left(2 a-w_{s}-\lambda c_{f}\right)}{2 K_{1}}, \\
q_{p}^{\mathrm{CS} *}=\frac{2 k(\beta+1)\left((1-\beta)\left(a-w_{s}\right)-u\right)+\theta^{2} \gamma^{2}\left(2 u+(1-\beta)\left(w_{s}-\lambda c_{f}\right)\right)}{4 K_{1}\left(1-\beta^{2}\right)}, \\
q_{s}^{\mathrm{CS} *}=\frac{2 k(\beta+1)\left((1-\beta)\left(a-w_{s}\right)+u \beta\right)-\theta^{2} \gamma^{2}\left((\beta-1)\left(w_{s}-\lambda c_{f}\right)+2 u \beta\right)}{4 K_{1}\left(1-\beta^{2}\right)} .
\end{gathered}
$$

Proof of Corollary 3. From the formula (A.22)-(A.25), the first-order partial derivative of $c_{f}, \gamma, k$, and $\beta$ can be shown as

$$
\begin{aligned}
& \frac{\partial q_{P}^{\mathrm{CS} *}}{\partial c_{f}}=-\frac{\theta^{2} \gamma^{2} \lambda}{4 K_{1}(\beta+1)}<0, \\
& \frac{\partial q_{s}^{\mathrm{CS} *}}{\partial c_{f}}=-\frac{\theta^{2} \gamma^{2} \lambda}{4 K_{1}(\beta+1)}<0, \\
& \frac{\partial t_{p}^{\mathrm{CS} *}}{\partial c_{f}}=-\frac{\theta \gamma \lambda}{2 K_{1}}<0,
\end{aligned}
$$




$$
\begin{aligned}
\frac{\partial \mu^{\mathrm{CS} *}}{\partial c_{f}}= & \frac{\lambda K_{1}\left(2 a-u-2 w_{s}\right)}{k(\beta+1)\left(2 a-w_{s}-\lambda c_{f}\right)^{2}}>0, \\
\frac{\partial q_{p}^{\mathrm{CS} *}}{\partial \gamma}= & \frac{\theta^{2} k \gamma\left(2 a-w_{s}-\lambda c_{f}\right)}{2\left(-k+\theta^{2} \gamma^{2}-k \beta\right)^{2}}>0, \\
\frac{\partial q_{s}^{\mathrm{CS} *}}{\partial \gamma}= & \frac{\theta^{2} k \gamma\left(2 a-w_{s}-\lambda c_{f}\right)}{2\left(-k+\theta^{2} \gamma^{2}-k \beta\right)^{2}}>0, \\
\frac{\partial t_{p}^{\mathrm{CS} *}}{\partial \gamma}= & \frac{\theta\left(k+\theta^{2} \gamma^{2}+k \beta\right)\left(2 a-w_{s}-\lambda c_{f}\right)}{2\left(-k+\theta^{2} \gamma^{2}-k \beta\right)^{2}}>0, \\
\frac{\partial \mu^{\mathrm{CS} *}}{\partial \gamma}= & \frac{2 \theta^{2} \gamma\left(u+w_{s}-\lambda c_{f}\right)}{k(\beta+1)\left(2 a-w_{s}-\lambda c_{f}\right)}>0, \\
\frac{\partial q_{p}^{\mathrm{CS} *}}{\partial k}= & -\frac{\theta^{2} \gamma^{2}\left(2 a-w_{s}-\lambda c_{f}\right)}{4\left(-k+\theta^{2} \gamma^{2}-k \beta\right)^{2}}<0, \\
\frac{\partial q_{s}^{\mathrm{CS} *}}{\partial k}= & -\frac{\theta^{2} \gamma^{2}\left(2 a-w_{s}-\lambda c_{f}\right)}{4\left(-k+\theta^{2} \gamma^{2}-k \beta\right)^{2}}<0, \\
\frac{\partial t_{p}^{\mathrm{CS} *}}{\partial k}= & -\frac{\theta \gamma(\beta+1)\left(2 a-w_{s}-\lambda c_{f}\right)}{2\left(-k+\theta^{2} \gamma^{2}-k \beta\right)^{2}}<0, \\
\frac{\partial \mu^{\mathrm{CS} *}}{\partial k}= & \frac{\theta^{2} \gamma^{2}\left(u+w_{s}-\lambda c_{f}\right)}{k^{2}(\beta+1)\left(w_{s}+\lambda c_{f}-2 a\right)}<0 ; \\
\frac{\partial q_{p}^{\mathrm{CS} *}}{\partial \beta}= & -\frac{2 k^{2}(\beta+1)^{2}\left((\beta-1)^{2}\left(a-w_{s}\right)+2 u \beta\right)+\theta^{2} \gamma^{2}\left(-2 k-2 k \beta+\theta^{2} \gamma^{2}\right)\left((\beta-1)^{2}\left(\lambda c_{f}-w_{s}\right)+4 u \beta\right)}{4 K_{1}^{2}\left(\beta^{2}-1\right)^{2}} .
\end{aligned}
$$

Let $f(k)=2 k^{2}(\beta+1)^{2}\left((\beta-1)^{2}\left(a-w_{s}\right)+2 u \beta\right)+\theta^{2} \gamma^{2}$ $\left(-2 k \quad-2 k \beta+\theta^{2} \gamma^{2}\right)\left((\beta-1)^{2}\left(\lambda c_{f}-w_{s}\right)+4 u \beta\right), \quad f^{\prime}(k)$ $=4(\beta+1)^{2} \quad\left((\beta-1)^{2}\left(a-w_{s}\right)+2 u \beta\right)>0, \quad(1-\beta)\left(a-w_{s}\right.$ $\left.+\theta \gamma K_{2}\left(u+w_{s}-\lambda c_{f}\right)\right) \geq u$ and $f\left(k=\left(\begin{array}{ll}\theta^{2} \gamma^{2} & / 2 \beta))\end{array}\right.\right.$

$$
\begin{aligned}
& \frac{\partial q_{s}^{\mathrm{CS} *}}{\partial \beta}=\frac{-2 k^{2}(\beta+1)^{2}\left((\beta-1)^{2}\left(a-w_{s}\right)-u\left(\beta^{2}+1\right)\right)+\theta^{2} \gamma^{2}\left(-2 k+\theta^{2} \gamma^{2}-2 k \beta\right)\left(2 u\left(\beta^{2}+1\right)+(\beta-1)^{2}\left(w_{s}-\lambda c_{f}\right)\right)}{4\left(\beta^{2}-1\right)^{2}\left(k+k \beta-\theta^{2} \gamma^{2}\right)^{2}}<0, \\
& \frac{\partial t_{p}^{\mathrm{CS} *}}{\partial \beta}=\frac{\theta \gamma k\left(w_{s}-2 a+\lambda c_{f}\right)}{2\left(k+k \beta-\theta^{2} \gamma^{2}\right)^{2}}<0 ; \\
& \frac{\partial \mu^{\mathrm{CS} *}}{\partial \beta}=\frac{\theta^{2} \gamma^{2}\left(u+w_{s}-\lambda c_{f}\right)}{k(\beta+1)^{2}\left(w_{s}+\lambda c_{f}-2 a\right)}<0 .
\end{aligned}
$$

Proof of Proposition 4. From the equation (10), the firstorder partial derivatives of $q_{p}$ and $q_{s}$ can be shown as follows: $=\theta^{4} \gamma^{4}(\beta-1)^{2} \quad\left(\left((\beta-1)\left(a-w_{s} \quad+a \beta-\beta \lambda c_{f}\right)\right.\right.$ $\left.-2 u \beta) / 2 \beta^{2}\right)>0$, thus $f(k)>0$.

Similarly, 


$$
\begin{gathered}
q_{p}^{\mathrm{QC}}=\frac{(\beta-1)\left(a-w_{s}+\theta \gamma t_{p}\right)+u-\tau}{2\left(\beta^{2}-1\right)}, \\
q_{s}^{\mathrm{QC}}=\frac{(\beta-1)\left(a-w_{s}+\theta \gamma t_{p}\right)+\beta(\tau-u)}{2\left(\beta^{2}-1\right)} .
\end{gathered}
$$

Taking (A.28) and (A.29) into (9) and calculating the first-order partial derivatives of $t_{p}$, $\tau$, we have

$$
\begin{gathered}
\tau=u+w_{s}+\beta \lambda c_{f}, \\
t_{p}^{\mathrm{QC} *}=\frac{\theta \gamma\left(2 a-w_{s}-\lambda c_{f}\right)}{2 K_{1}} .
\end{gathered}
$$

We take (A.30) and (A.31) into (A.28) and (A.29) the equilibrium solutions are as follows:

$$
\begin{gathered}
q_{p}^{\mathrm{QC} *}=\frac{2 a k(1-\beta)+\left(w_{s}+\lambda c_{f}\right)\left(2 k \beta-\theta^{2} \gamma^{2}\right)}{4 K_{1}(1-\beta)}, \\
q_{s}^{\mathrm{QC} *}=\frac{2 a k(1-\beta)-\lambda c_{f}\left(2 k \beta^{2}-\theta^{2} \gamma^{2}(2 \beta-1)\right)-w_{s}\left(2 k-\theta^{2} \gamma^{2}\right)}{4 K_{1}(1-\beta)} .
\end{gathered}
$$

Proof of Corollary 4. From the equation (A.31)-(A.33), the partial derivative of $c_{f}, \gamma, k$, and $\beta$, we get

$$
\begin{aligned}
& \frac{\partial q_{p}^{\mathrm{QC} *}}{\partial c_{f}}=-\frac{\lambda\left(\theta^{2} \gamma^{2}-2 k \beta\right)}{4(\beta-1)\left(-k+\theta^{2} \gamma^{2}-k \beta\right)}>0, \\
& \frac{\partial q_{s}^{\mathrm{QC} *}}{\partial c_{f}}=\frac{\left(-\theta^{2} \gamma^{2}-2 k \beta^{2}+2 \theta^{2} \gamma^{2} \beta\right) \lambda}{4(\beta-1)\left(-k+\theta^{2} \gamma^{2}-k \beta\right)}<0, \\
& \frac{\partial t_{p}^{\mathrm{QC} *}}{\partial c_{f}}=\frac{\theta \lambda \gamma}{2\left(-k+\theta^{2} \gamma^{2}-k \beta\right)}<0 ; \\
& \frac{\partial q_{p}^{\mathrm{QC} *}}{\partial \gamma}=\frac{\theta^{2} \gamma k\left(2 a-w_{s}-\lambda c_{f}\right)}{2\left(-k+\theta^{2} \gamma^{2}-k \beta\right)^{2}}>0, \\
& \frac{\partial q_{s}^{\mathrm{QC} *}}{\partial \gamma}=\frac{\theta^{2} \gamma k\left(2 a-w_{s}-\lambda c_{f}\right)}{2\left(-k+\theta^{2} \gamma^{2}-k \beta\right)^{2}}>0, \\
& \frac{\partial t_{p}^{\mathrm{QC} *}}{\partial \gamma}=\frac{\theta\left(k+\theta^{2} \gamma^{2}+k \beta\right)\left(2 a-w_{s}-\lambda c_{f}\right)}{2\left(-k+\theta^{2} \gamma^{2}-k \beta\right)^{2}}>0 ; \\
& \frac{\partial q_{p}^{\mathrm{QC} *}}{\partial k}=-\frac{\theta^{2} \gamma^{2}\left(2 a-w_{s}-\lambda c_{f}\right)}{4\left(-k+\theta^{2} \gamma^{2}-k \beta\right)^{2}}<0, \\
& \frac{\partial q_{s}^{\mathrm{QC} *}}{\partial k}=-\frac{\theta^{2} \gamma^{2}\left(2 a-w_{s}-\lambda c_{f}\right)}{4\left(-k+\theta^{2} \gamma^{2}-k \beta\right)^{2}}<0, \\
& \frac{\partial t_{p}^{\mathrm{QC} *}}{\partial k}=-\frac{\theta \gamma(\beta+1)\left(2 a-w_{s}-\lambda c_{f}\right)}{2\left(-k+\theta^{2} \gamma^{2}-k \beta\right)}<0 ; \\
& \frac{\partial q_{p}^{\mathrm{QC} *}}{\partial \beta}=-\frac{2 a k^{2}(\beta-1)^{2}-\left(2 k^{2}\left(\beta^{2}+1\right)+\theta^{2} \gamma^{2}\left(-2 k+\theta^{2} \gamma^{2}-2 k \beta\right)\right)\left(w_{s}+\lambda c_{f}\right)}{4(\beta-1)^{2}\left(-k+\theta^{2} \gamma^{2}-k \beta\right)^{2}} \text {. }
\end{aligned}
$$


Let $f(k)=2 a k^{2}(\beta-1)^{2}-\left(2 k^{2}\left(\beta^{2}+1\right)+\theta^{2} \gamma^{2}\left(-2 k+\theta^{2} \gamma^{2}\right.\right.$ $-2 k \beta))\left(w_{s}+\lambda c_{f}\right)$, we have $f^{\prime \prime}(k)=4\left(a(\beta-1)^{2}-\left(\beta^{2}+1\right)\right.$

$\left.\left(w_{s}+\lambda c_{f}\right)\right)>0$,

$$
\begin{gathered}
f^{\prime}\left(k=\frac{\theta^{2} \gamma^{2}}{\beta+1}\right)=2 \theta^{2} \gamma^{2}(\beta-1)^{2} \frac{2 a-w_{s}-\lambda c_{f}}{\beta+1}>0, \\
f\left(k=\frac{\theta^{2} \gamma^{2}}{\beta+1}\right)=\theta^{4} \gamma^{4}(\beta-1)^{2} \frac{2 a-w_{s}-\lambda c_{f}}{(\beta+1)^{2}}>0,
\end{gathered}
$$

and thus, $\left(\partial q_{p}^{\mathrm{QC} *} / \partial \beta\right)<0$.

$$
\begin{aligned}
\frac{\partial q_{s}^{\mathrm{QC} *}}{\partial \beta} & =-\frac{2 a k^{2}(\beta-1)^{2}+\left(\theta^{2} \gamma^{2}-2 k\right)\left(\theta^{2} \gamma^{2}-2 k \beta\right)\left(w_{s}+\lambda c_{f}\right)}{4(\beta-1)^{2}\left(-k+\theta^{2} \gamma^{2}-k \beta\right)^{2}}<0, \\
\frac{\partial t_{p}^{\mathrm{QC} *}}{\partial \beta} & =-\theta k \gamma \frac{2 a-w_{s}-\lambda c_{f}}{2\left(-k+\theta^{2} \gamma^{2}-k \beta\right)^{2}}<0 .
\end{aligned}
$$

Proof of Corollary 5. From (A.7), (A.13), (A.23) and (A.31), we get $t_{p}^{\mathrm{QC} *}=t_{p}^{\mathrm{CS} *}=t_{p}^{\mathrm{CD} *}$,

$$
t_{p}^{\mathrm{CD} *}-t_{p}^{\mathrm{DD} *}=\theta \gamma \frac{k(\beta+1)\left(2 a-u-2 w_{s}\right)+\theta^{2} \gamma^{2}\left(u+w_{s}-\lambda c_{f}\right)}{2 k K_{1}(\beta+1)}>0
$$

and thus, $t_{p}^{\mathrm{CD} *}=t_{p}^{\mathrm{QC} *}=t_{p}^{\mathrm{CS} *}>t_{p}^{\mathrm{DD} *}$.

Proof of Corollary 6. From (A.5), (A.14), (A.24) and (A.32), we have $q_{p}^{\mathrm{CS} *}-q_{p}^{\mathrm{QC} *}=\left(\left(u+w_{s}+\beta \lambda c_{f}\right) / 2\left(\beta^{2}-1\right)\right)<0$ and $q_{p}^{\mathrm{CS} *}-q_{p}^{\mathrm{DD} *}=\theta^{2} \gamma^{2} \quad\left(\left(k(\beta+1)\left(2 a-u-2 w_{s}\right)+\theta^{2} \gamma^{2}\right.\right.$ $\left.\left.\left(u+w_{s}-\lambda c_{f}\right)\right) /\left(4 K_{1}(\beta+1)^{2}\right)\right)>0$.
Hence, $q_{p}^{\mathrm{QC} *}>q_{p}^{\mathrm{DD} *}$ and $q_{p}^{\mathrm{QC} *}=q_{p}^{\mathrm{CD} *}$.

Proof of Corollary 7. From (A.6), (A.15), (A.25), and (A.33), we have $q_{s}^{\mathrm{CS} *}-q_{s}^{\mathrm{QC} *}=\beta\left(\left(u+w_{s}+\beta \lambda c_{f}\right) / 2\left(1-\beta^{2}\right)\right)>0$,

$$
q_{s}^{\mathrm{CS} *}-q_{s}^{\mathrm{DD} *}=\theta^{2} \gamma^{2} \frac{k(\beta+1)\left(2 a-u-2 w_{s}\right)+\theta^{2} \gamma^{2}\left(u+w_{s}-\lambda c_{f}\right)}{4 k K_{1}(\beta+1)^{2}}>0
$$

and $q_{s}^{\mathrm{QC} *}-q_{s}^{\mathrm{DD} *}=\left(\left(2 k^{2} \beta(\beta+1)^{2}\left(u+w_{s}+\beta \lambda c_{f}\right)\right.\right.$ $\left.\left.+f\left(\theta^{2} \gamma^{2}\right)\right) /\left(4 K_{1} k(\beta-1)(\beta+1)^{2}\right)\right)$.

Let $f\left(\theta^{2} \gamma^{2}\right)=\theta^{2} \gamma^{2}[k(\beta+1)(2 a(\beta-1)-u(3 \beta-1)-$ $\left.\left.2 w_{s}(2 \beta-1)-2 \beta^{2} \lambda c_{f}\right)+\theta^{2} \gamma^{2}\left(u+w_{s}-\lambda c_{f}\right)(\beta-1)\right]$ and $g\left(\theta^{2} \gamma^{2}\right)=2 k^{2} \beta(\beta+1)^{2}\left(u+w_{s}+\beta \lambda c_{f}\right)+f\left(\theta^{2} \gamma^{2}\right), g^{\prime}\left(\theta^{2} \gamma^{2}\right)$
$<0, \quad g(0)=2 k^{2} \beta(\beta+1)^{2}\left(u+w_{s}+\beta \lambda c_{f}\right)>0 \quad$ and $g(k(\beta+1))=k^{2}(\beta-1)(\beta+1)^{2}\left(2 a-w_{s}-\lambda c_{f}\right)<0$.

Hence, there must be $\bar{\varphi}>0$ that makes $g(\bar{\varphi})=0$ and $\bar{\varphi}=g^{-1}(0)$. Especially, $g\left(\theta^{2} \gamma^{2}\right)>0$ when $\theta^{2} \gamma^{2} \in(0, \bar{\varphi}]$ and $g\left(\theta^{2} \gamma^{2}\right)<0$ when $\theta^{2} \gamma^{2} \in(\bar{\varphi}, k(\beta+1)]$. 
Therefore, when $0<\theta^{2} \gamma^{2}<\bar{\varphi}, \quad q_{s}^{\mathrm{QC} *}<q_{s}^{\mathrm{DD} *}$; when $\bar{\varphi}<\theta^{2} \gamma^{2}<k(\beta+1) \cdot q_{s}^{\mathrm{DD} *}<q_{s}^{\mathrm{QC} *}$.
Proof of Corollary 8. From (A.6), (A.15), (A.25), and (A.33), we have

$$
\begin{aligned}
r_{s}^{\mathrm{CD} *} & =\frac{q_{s}^{\mathrm{CD} *}}{q_{s}^{\mathrm{CD} *}+q_{p}^{\mathrm{CD} *}}=\frac{2 a k(\beta-1)+\left(w_{s}+\lambda c_{f}\right)\left(2 k-\theta^{2} \gamma^{2}\right)}{2 k(\beta-1)\left(2 a-w_{s}-\lambda c_{f}\right)}, \\
r_{s}^{\mathrm{DD} *} & =\frac{q_{s}^{\mathrm{DD} *}}{q_{s}^{\mathrm{DD} *}+q_{p}^{\mathrm{DD} *}}=\frac{2 a k\left(1-\beta^{2}\right)+2 k(\beta+1)\left(-w_{s}+u \beta+\beta w_{s}\right)+\theta^{2} \gamma^{2}(1-\beta)\left(u+w_{s}-\lambda c_{f}\right)}{2(1-\beta)\left(k(\beta+1)\left(2 a-u-2 w_{s}\right)+\theta^{2} \gamma^{2}\left(u+w_{s}-\lambda c_{f}\right)\right)}, \\
r_{s}^{\mathrm{CS} *} & =\frac{q_{s}^{\mathrm{CS} *}}{q_{s}^{\mathrm{CS} *}+q_{p}^{\mathrm{CS} *}}=\frac{2 a k\left(1-\beta^{2}\right)+2 k(\beta+1)\left(-w_{s}+u \beta+\beta w_{s}\right)-\theta^{2} \gamma^{2}\left(2 u \beta+(\beta-1)\left(w_{s}-\lambda c_{f}\right)\right)}{(1-\beta)\left(k(\beta+1)\left(2 a-u-2 w_{s}\right)+\theta^{2} \gamma^{2}\left(u+w_{s}-\lambda c_{f}\right)\right)}, \\
r_{s}^{\mathrm{QC} *} & =\frac{q_{s}^{\mathrm{QC} *}}{q_{s}^{\mathrm{QC} *}+q_{p}^{\mathrm{QC} *}}=\frac{2 a k(1-\beta)-2 k\left(w_{s}+\beta^{2} \lambda c_{f}\right)+\theta^{2} \gamma^{2}\left(w_{s}-\lambda c_{f}+2 \beta \lambda c_{f}\right)}{2(1-\beta)\left(-k w_{s}+2 a k-\theta^{2} \gamma^{2} \lambda c_{f}+k \beta \lambda c_{f}\right)}, \\
r_{s}^{\mathrm{DD} *}-r_{s}^{\mathrm{CS} *} & =\theta^{2} \gamma^{2} u \frac{\beta+1}{2(1-\beta)\left(k(\beta+1)\left(2 a-u-2 w_{s}\right)+\theta^{2} \gamma^{2}\left(u+w_{s}-\lambda c_{f}\right)\right)}>0, \\
r_{s}^{\mathrm{CS} *}-r_{s}^{\mathrm{QC} *} & =\frac{K_{1}\left(2 k(\beta+1)\left(a-w_{s}\right)+\theta^{2} \gamma^{2}\left(w_{s}-\lambda c_{f}\right)\right)\left(u+w_{s}+\beta \lambda c_{f}\right)}{(1-\beta)\left(k\left(2 a-w_{s}\right)+\lambda c_{f}\left(k \beta-\theta^{2} \gamma^{2}\right)\right)\left(k(\beta+1)\left(2 a-u-2 w_{s}\right)+\theta^{2} \gamma^{2}\left(u+w_{s}-\lambda c_{f}\right)\right)}>0 .
\end{aligned}
$$

Thus, we get $r_{s}^{\mathrm{DD} *}>r_{s}^{\mathrm{CS} *}>r_{s}^{\mathrm{QC} *}>r_{s}^{\mathrm{CD} *}$ and similarly, Proof of Corollary 9. From the above proposition, we have $r_{p}^{\mathrm{SC} *}>r_{p}^{\mathrm{QC} *}>r_{p}^{\mathrm{CS} *}>r_{p}^{\mathrm{DD} *}$.

$$
\begin{aligned}
\Pi_{p}^{\mathrm{CS} *} & =\frac{4 k(\beta+1)\left[a\left(u-\lambda c_{f}\right)(\beta-1)+u\left(u+\beta \lambda c_{f}\right)\right]}{8 K_{1}\left(\beta^{2}-1\right)}, \\
\Pi_{R}^{\mathrm{CS} *} & =\frac{2 k(\beta+1)\left[2 a(\beta-1)(a-u)-u^{2}\right]+\theta^{2} \gamma^{2}\left[2 u(a \beta-a+u)+\lambda c_{f}(\beta-1)(u-2 a)\right]}{8 K_{1}\left(\beta^{2}-1\right)}, \\
\Pi_{p}^{\mathrm{DD} *} & =\frac{a u(1-\beta)-u^{2}-\lambda c_{f}(a-a \beta+\beta u)-K_{2}\left(\lambda c_{f}-u\right)^{2}(\beta-1)\left(\theta \gamma-k K_{2}-k \beta K_{2}\right)}{2\left(1-\beta^{2}\right)}, \\
\Pi_{R}^{\mathrm{DD} *} & =\frac{2 a(\beta-1)(a-u)-u^{2}-2 \theta \gamma K_{2}(\beta-1)\left(\lambda c_{f}-u\right)\left[2 a-u+\theta \gamma K_{2}\left(u-\lambda c_{f}\right)\right]}{4\left(\beta^{2}-1\right)} .
\end{aligned}
$$

$\Pi_{p}^{\mathrm{CS} *}-\Pi_{p}^{\mathrm{DD} *}=\left(\left(\theta^{2} \gamma^{2}\left(u-\lambda c_{f}\right)[k(\beta+1)(2 a-u)\right.\right.$ $\left.\left.\left.+\theta^{2} \gamma^{2^{p}}\left(u-\lambda c_{f}\right)\right]\right) /\left(8 k K_{1}(\beta+1)^{2}\right)\right)>0$ because of $2 k \beta>\theta^{2} \gamma^{2}$ and $k \geq\left(\left(\theta \gamma\left(2 a-w_{s}-\lambda c_{f}\right)+2 \theta^{2} \gamma^{2}\right) / 2(1+\beta)\right)$. Similarly, $\Pi_{R}^{\mathrm{CS} *}-\Pi_{R}^{\mathrm{DD} *}=\left(\theta^{2} \gamma^{2}\left[k(\beta+1)\left(2 a-2 u+\lambda c_{f}\right)+\theta^{2} \gamma^{2}\left(w_{p}\right.\right.\right.$ $\left.\left.\left.-\lambda c_{f}\right)\right]\left[k(\beta+1)(2 a-u)+\theta^{2} \gamma^{2}\left(u-\lambda c_{f}\right)\right]\right) /\left(8 K_{1} k^{2}(\beta+1)^{3}\right)^{p}$.
Let $f(k)=k(\beta+1)(2 a-u)+\theta^{2} \gamma^{2}\left(u-\lambda c_{f}\right), \quad(\partial f(k)$ $/ \partial k)=(\beta+1)(2 a-u)>0$ and $k>\left(\theta^{2} \gamma^{2} /(\beta+1)\right)$, which show that $f\left(k=\left(\theta^{2} \gamma^{2} /(\beta+1)\right)\right)=\theta^{2} \gamma^{2}\left(2 a-\lambda c_{f}\right)>0$ and $f(k)=k(\beta+1)(2 a-u)+\theta^{2} \gamma^{2}\left(u-\lambda c_{f}\right)>0$, thus $\Pi_{R}^{\mathrm{CS} *}$ $>\Pi_{R}^{\mathrm{DD} *}$. 
Proof of Corollary 10. From profit of platform and retailer, we have

$$
\begin{aligned}
\Pi_{C}^{\mathrm{CD} *} & =\frac{4 a k(1-\beta)\left(a-\lambda c_{f}\right)+\lambda^{2} c_{f}^{2}\left(2 k-\theta^{2} \gamma^{2}\right)}{8(1-\beta) K_{1}}, \\
\Pi_{C}^{\mathrm{CD} *} & =\frac{u\left(u+2 \beta \lambda c_{f}\right)+2 a(\beta-1)\left(a-\lambda c_{f}\right)-2 K_{2}\left(\lambda c_{f}-u\right)(\beta-1)\left[\theta \gamma\left(2 a-\lambda c_{f}\right)+K_{2} K_{1}\left(\lambda c_{f}-u\right)\right]}{4\left(\beta^{2}-1\right)}, \\
\Pi_{C}^{\mathrm{CS} *} & =\frac{2 K_{1} u\left(u+2 \beta \lambda c_{f}\right)+\theta^{2} \lambda^{2} \gamma^{2} c_{f}^{2}(\beta-1)+4 a k\left(\beta^{2}-1\right)\left(a-\lambda c_{f}\right)}{8 K_{1}\left(\beta^{2}-1\right)}, \\
\Pi_{C}^{\mathrm{QC} *} & =\frac{4 a k(\beta-1)\left(a-\lambda c_{f}\right)+\lambda^{2} c_{f}^{2}\left(-2 k \beta^{2}+\theta^{2} \gamma^{2}(2 \beta-1)\right)}{8(\beta-1) K_{1}}, \\
\Pi_{C}^{C S *}-\Pi_{C}^{D D *} & =\frac{\theta^{2} \gamma^{2}\left(-k u+2 a k+2 a k \beta+\theta^{2} \gamma^{2} u-k \beta u-\theta^{2} \gamma^{2} \lambda c_{f}\right)^{2}}{8 k^{2}(\beta+1)^{3} K_{1}}>0, \\
\Pi_{C}^{\mathrm{CS} *}-\Pi_{C}^{\mathrm{QC} *} & =\frac{\left(u+\beta \lambda c_{f}\right)^{2}}{4\left(\beta^{2}-1\right)}<0, \\
\Pi_{C}^{\mathrm{QC} *}-\Pi_{C}^{\mathrm{CD} *} & =-\frac{1}{4} \lambda^{2} c_{f}^{2}<0 .
\end{aligned}
$$

Hence, $\Pi_{C}^{\mathrm{CD} *}>\Pi_{C}^{\mathrm{QC} *}>\Pi_{C}^{\mathrm{CS} *}>\Pi_{C}^{\mathrm{DD} *}$.

$$
\prod_{p}^{\mathrm{QC} *}=\frac{8 T u K_{1}^{2}-4 a^{2} \theta^{2} k \gamma^{2}+\lambda c_{f}\left[\theta^{2} \gamma^{2}\left[4 a k(\beta+2)+\lambda c_{f}\left(K_{1}+k \beta-\theta^{2} \gamma^{2}\right)\right]-4 a k^{2}(\beta+1)^{2}+8 T \beta K_{1}^{2}\right]}{8 K_{1}^{2}},
$$

$$
\begin{aligned}
& \prod_{R}^{\mathrm{QC} *} \\
& =\frac{4(\beta-1)\left(-a^{2} k^{2}(\beta+1)+2 T u K_{1}^{2}\right)+\lambda c_{f}\left[8 T \beta(\beta-1) K_{1}^{2}+4 a k\left(\beta^{2}-1\right)\left(\theta^{2} \gamma^{2}-k \beta\right)+\lambda c_{f}\left[\theta^{4} \gamma^{4}-2 k \beta(\beta+1)\left(\theta^{2} \gamma^{2}-k \beta\right)\right]\right]}{8 K_{1}^{2}(1-\beta)} .
\end{aligned}
$$

From (A.42) and (A.43), the partial derivative of equilibrium with $T$ can be shown as $\left(\partial \Pi_{p}^{\mathrm{QC} *} / \partial T\right)=u+\beta \lambda c_{f}>0$, and $\left(\partial \Pi_{R}^{\mathrm{QC} *} / \partial T\right)=-\left(u+\beta \lambda c_{f}\right)<0$.

$$
\begin{aligned}
& T_{1}=\frac{4 k a^{2} \theta^{2} \gamma^{2}-\lambda c_{f}\left(-4 a k^{2}(\beta+1)^{2}+\theta^{2} \gamma^{2}\left(\lambda c_{f}\left(K_{1}-\theta^{2} \gamma^{2}+k \beta\right)+4 a k(\beta+2)\right)\right)}{8 K_{1}^{2}\left(u+\beta \lambda c_{f}\right)}, \\
& T_{4}=\frac{4 a^{2} k^{2}\left(\beta^{2}-1\right)-\lambda c_{f}\left[\lambda c_{f}\left(\theta^{4} \gamma^{4}-2 k \beta\left(\theta^{2} \gamma^{2}-k \beta\right)(\beta+1)\right)+4 a k\left(\theta^{2} \gamma^{2}-k \beta\right)\left(\beta^{2}-1\right)\right]}{8 K_{1}^{2}(\beta-1)\left(u+\beta \lambda c_{f}\right)} .
\end{aligned}
$$


$T_{4}-T_{1}=-\left(\left(4 a k(\beta-1)\left(a-\lambda c_{f}\right)+\lambda^{2} c_{f}^{2}\right.\right.$ $\left.\left.\left.\left(\theta^{2} \gamma^{2}-k \beta\right)-\theta^{2} \gamma^{2}\right]\right) /\left(8 K_{1}(1-\beta)\left(u+\beta \lambda c_{f}\right)\right)\right)>0$, $T \in\left(T_{1}, T_{4}\right)$ because of $\Pi_{p}^{\mathrm{QC} *}>0$ and $\Pi_{R}^{\mathrm{QC} *}>0$.
$[2 \beta$

where
Similarly, let $\Pi_{P}^{\mathrm{QC}}\left(T=T_{2}\right)=\Pi_{P}^{\mathrm{DC}}, \Pi_{R}^{\mathrm{QC}}\left(T=T_{3}\right)=\Pi_{R}^{\mathrm{DC}}$, we have $T_{2}=\left(\left(R_{2}+R_{3}\right) /\left(w_{p}+\beta \lambda c_{f}\right)\right), \quad T_{3}=-\left(\left(R_{4}\right.\right.$ $\left.\left.+R_{5}\right) /\left(u+\beta \lambda c_{f}\right)\right)$, where

$$
\begin{aligned}
R_{2} & =\frac{1}{2\left(\beta^{2}-1\right)}\left(u\left(u+\beta \lambda c_{f}\right)+\frac{1}{2}\left(u-\lambda c_{f}\right)(\beta-1)\left(2 a+\theta \gamma \varphi\left(u-\lambda c_{f}\right)\right)\right), \\
R_{3} & =-\frac{1}{8 K_{1}^{2}}\left(\lambda c_{f}\left(-4 a k^{2}(\beta+1)^{2}+\theta^{2} \gamma^{2}\left(\lambda c_{f}\left(K_{1}-\theta^{2} \gamma^{2}+k \beta\right)+4 a k(\beta+2)\right)\right)-4 a^{2} \theta^{2} \gamma^{2} k\right), \\
R_{4} & =\frac{1}{4\left(\beta^{2}-1\right)}\left(-u^{2}+2 a(\beta-1)(a-u)+2 \theta \gamma \varphi(\beta-1)\left(u-\lambda c_{f}\right)\left(2 a-u+\theta \gamma \varphi\left(u-\lambda c_{f}\right)\right)\right), \\
R_{5}= & \frac{\lambda c_{f}\left(\lambda c_{f}\left(\theta^{4} \gamma^{4}-2 k \beta\left(\theta^{2} \gamma^{2}-k \beta\right)(\beta+1)\right)+4 a k\left(\theta^{2} \gamma^{2}-k \beta\right)\left(\beta^{2}-1\right)\right)-4 a^{2} k^{2}\left(\beta^{2}-1\right)}{8 K_{1}^{2}(\beta-1)}, \\
T_{2}-T_{3}= & \frac{8 a \theta \gamma \varphi K_{1}(\beta-1)\left(u K_{1}-a k(\beta+1)+\theta^{2} \gamma^{2} \lambda c_{f}\right)+2 K_{1}^{2} u^{2}(\theta \gamma \varphi(\beta-1)(2 \theta \gamma \varphi-1)+1)+R_{6}}{8 K_{1}^{2}\left(\beta^{2}-1\right)\left(u+\beta \lambda c_{f}\right)},
\end{aligned}
$$

where $\quad R_{6}=\lambda c_{f}\left(-4 K_{1}^{2} u\left(2 \theta^{2} \gamma^{2} \varphi^{2} \quad(\beta-1)-\beta\right)+\lambda c_{f} K_{1}\right.$ $\left.\left(2 \beta^{2} K_{1}-4 \varphi^{2} \theta^{4} \gamma^{4}(\beta-1)\right)\right)>0$. We have $T_{2}<T_{3}$.
Let $f(T)=\Pi_{R}^{\mathrm{CS} *}-\Pi_{R}^{\mathrm{QC} *}$, we have $f^{\prime}(T)=u+\beta \lambda c_{f}>0$, and when $f(T)=0, T_{6}=-\left(\left(R_{7}+R_{8}\right) /\left(u+\beta \lambda c_{f}\right)\right)$, where

$$
\begin{aligned}
& R_{7}=\frac{4 a k\left(\beta^{2}-1\right)\left(a k-\lambda c_{f}\left(\theta^{2} \gamma^{2}-k \beta\right)\right)-\lambda^{2} c_{f}^{2}\left(\theta^{4} \gamma^{4}-2 k \beta(\beta+1)\left(\theta^{2} \gamma^{2}-k \beta\right)\right)}{8(1-\beta) K_{1}^{2}}, \\
& R_{8}=\frac{2 u^{2} K_{1}-(\beta-1)\left(4 a k(\beta+1)(a-u)+\theta^{2} \gamma^{2}\left(2 a\left(u-\lambda c_{f}\right)+\lambda u c_{f}\right)\right)}{8\left(1-\beta^{2}\right) K_{1}} .
\end{aligned}
$$

Similarly, let $g(T)=\Pi_{P}^{\mathrm{CS} *}-\Pi_{P}^{\mathrm{QC} *}$, we have $g^{\prime}(T)=-\left(u+\beta \lambda c_{f}\right)<0, \quad$ and when $g(T)=0$, $T_{5}=-\left(\left(R_{9}+R_{10}\right) /\left(u+\beta \lambda c_{f}\right)\right)$, where

$$
\begin{aligned}
R_{9} & =\frac{\lambda c_{f}\left(\theta^{2} \gamma^{2}\left(\lambda c_{f}\left(k(2 \beta+1)-2 \theta^{2} \gamma^{2}\right)+4 a k(2+\beta)\right)-4 a k^{2}(\beta+1)^{2}\right)-4 a^{2} \theta^{2} \gamma^{2} k}{8 K_{1}^{2}}, \\
R_{10} & =\frac{a k\left(u-\lambda c_{f}\right)(\beta-1)+u k\left(u+\beta \lambda c_{f}\right)}{2 K_{1}(1-\beta)}, \\
T_{5}-T_{6} & =\frac{2 a \theta^{2} \gamma^{2}\left(\lambda c_{f}-u\right)(\beta-1)-u\left(2 k(\beta+1)\left(u+2 \beta \lambda c_{f}\right)+\theta^{2} \gamma^{2}\left(2 u+\lambda c_{f}(\beta-1)\right)\right)+\lambda^{2} c_{f}^{2}(\beta+1)\left(\theta^{2} \gamma^{2}(2 \beta-1)-2 k \beta^{2}\right)}{\left(1-\beta^{2}\right)\left(u+\beta \lambda c_{f}\right) K_{1}}<0 .
\end{aligned}
$$




\section{Data Availability}

The data used to support the findings of this study are included within the article.

\section{Conflicts of Interest}

The authors declare that they have no conflicts of interest.

\section{Acknowledgments}

Di Xiao acknowledges funding from the Philosophy and Social Science Program of Zhejiang Province (Grant 21NDJC079YB) and the Natural Science Foundation of Zhejiang Province (Grant LY18G020002). Qi Sun thank the financial support of Humanity and Social Science Foundation from the Ministry of Education of China (20YJC630130).

\section{References}

[1] P. Kotler and G. Armstrong, Principles of Marketing, Pearson, London, UK, 15 edition, 2014.

[2] A. J. H. Thorlakson and R. P. Murray, "An empirical study of empowerment in the workplace," Group and Organization Management, vol. 21, no. 1, pp. 67-83, 1996.

[3] S. Lenka, V. Parida, and J. Wincent, "Digitalization capabilities as enablers of value co-creation in servitizing Firms," Psychology and Marketing, vol. 34, no. 1, pp. 92-100, 2016.

[4] M. Corstjens and R. Lal, "Building store loyalty through store brands," Journal of Marketing Research, vol. 37, no. 3, pp. 281-291, 2000.

[5] S. Fiona, F. Morton, and Zettelmeyer, "The strategic positioning of store brands in retailer-manufacturer negotiations," Review of Industrial Organization, 2004.

[6] D. T. Mai, T. Liu, M. D. S. Morris, and S. Sun, "Quality coordination with extended warranty for store-brand products," European Journal of Operational Research, vol. 256, no. 2, pp. 524-532, 2017.

[7] W. Li, J. Chen, and B. Chen, "Supply chain coordination with customer returns and retailer's store brand product," International Journal of Production Economics, vol. 203, pp. 69-82, 2018.

[8] G. M. Grossman and C. Shapiro, "Comparative advantage in a multi-product and multi-factor model of multilateral trade," Contributions to Economic Analysis, vol. 78, no. 1, pp. 59-75, 1988.

[9] G. M. Grossman and C. Shapiro, "Foreign counterfeiting of status goods," The Quarterly Journal of Economics, vol. 103, no. 1, pp. 79-100, 1988.

[10] S.-H. Cho, X. Fang, and S. Tayur, "Combating strategic counterfeiters in licit and illicit supply chains," Manufacturing and Service Operations Management, vol. 17, no. 3, pp. 273289, 2015.

[11] C. Fershtman, "Identification of classes of differential games for which the open loop is a degenerate feedback Nash equilibrium," Journal of Optimization Theory and Applications, vol. 55, no. 2, pp. 217-231, 1987.

[12] V. P. Rindova, I. O. Williamson, A. P. Petkova, and J. M. Sever, "Being good or being known: an empirical examination of the dimensions, antecedents, and consequences of organizational reputation," Academy of Management Journal, vol. 48, no. 6, pp. 1033-1049, 2005.
[13] G. Feichtinger, R. F. Hartl, and S. P. Sethi, "Dynamic optimal control models in advertising: recent developments," Management Science, vol. 40, no. 2, pp. 195-226, 1994.

[14] N. Amrouche, G. Martín-Herrán, and G. Zaccour, "Feedback Stackelberg equilibrium strategies when the private label competes with the national brand," Annals of Operations Research, vol. 164, no. 1, pp. 79-95, 2008.

[15] P. De Giovanni, "Quality improvement vs. advertising support: which strategy works better for a manufacturer?" European Journal of Operational Research, vol. 208, no. 2, pp. 119-130, 2011.

[16] A. Nair and R. Narasimhan, "Dynamics of competing with quality- and advertising-based goodwill," European Journal of Operational Research, vol. 175, no. 1, pp. 462-474, 2006.

[17] F. El Ouardighi and F. Pasin, "Quality improvement and goodwill accumulation in a dynamic duopoly," European Journal of Operational Research, vol. 175, no. 2, pp. 1021-1032, 2006.

[18] S. L. Ting and A. H. C. Tsang, "Using social network analysis to combat counterfeiting," International Journal of Production Research, vol. 52, no. 15, pp. 4456-4468, 2013.

[19] Y. Qian, "Counterfeiters: foes or friends? how counterfeits affect sales by product quality tier," Management Science, vol. 60, no. 10, pp. 2381-2400, 2014.

[20] Y. Qian, Q. Gong, and Y. Chen, "Untangling searchable and experiential quality responses to counterfeits," Marketing Science, vol. 34, no. 4, pp. 522-538, 2015.

[21] K. Liu, J.-A. Li, Y. Wu, and K. K. Lai, "Analysis of monitoring and limiting of commercial cheating: a newsvendor model," Journal of the Operational Research Society, vol. 56, no. 7, pp. 844-854, 2005.

[22] P. E. Chaudhry, A. Zimmerman, J. R. Peters, and V. V. Cordell, "Preserving intellectual property rights: managerial insight into the escalating counterfeit market quandary," Business Horizons, vol. 52, no. 1, pp. 57-66, 2009.

[23] G. Häubl and V. Trifts, "Consumer decision making in online shopping environments: the effects of interactive decision aids," Marketing Science, vol. 19, no. 1, pp. 4-21, 2000.

[24] M. Q. Saeed, Z. Bilal, and C. D. Walter, "An NFC based consumer-level counterfeit detection framework," in Proceedings of the Eleventh International Conference on Privacy, IEEE, Tarragona, Catalonia, Spain, July 2013.

[25] K. L. Webb and J. E. Hogan, "Hybrid channel conflict: causes and effects on channel performance," Journal of Business and Industrial Marketing, vol. 17, no. 5, pp. 338-356, 2002.

[26] A. T. Coughlan, E. Anderson, L. W. Stern, and A. I. El-Ansary, Marketing Channels, Prentice Hall lnc, Hoboken, NJ, USA, 2001.

[27] L. J. Rosenberg and L. W. Stern, "Toward the analysis of conflict in distribution channels: a descriptive model," Journal of Marketing, vol. 34, no. 4, pp. 40-46, 1970.

[28] M. Etgar, "Sources and types of intrachannel conflict," Journal of Retailing, vol. 55, no. 01, pp. 61-78, 1976.

[29] J. R. Brown and R. L. Day, "Measures of manifest conflict in distribution channels," Journal of Marketing Research, vol. 18, no. 3, pp. 263-274, 1981.

[30] M. Duarte and G. Davies, "Testing the conflict-performance assumption in business-to-business relationships," Industrial Marketing Management, vol. 32, no. 2, pp. 91-99, 2003.

[31] S. A. Samaha, R. W. Palmatier and R. P. Dant, Poisoning relationships: perceived unfairness in channels of distribution," Journal of Marketing, vol. 75, no. 3, pp. 99-117, 2011. 
[32] S. J. Skinner, J. B. Gassenheimer, and S. W. Kelley, "Cooperation in supplier-dealer relations," Journal of Retailing, vol. 68, no. 2, pp. 174-193, 1992.

[33] J. R. Brown, R. F. Lusch, and L. P. Smith, "Conflict and satisfaction in an industrial channel of distribution," International Journal of Physical Distribution and Logistics Management, vol. 21, no. 6, pp. 15-26, 2016.

[34] W. Baker, M. Marn, and C. Zawada, "Price smarter on the net," Harvard Business Review, vol. 79, no. 2, pp. 122-157, 2001.

[35] K. L. Webb, "Managing channels of distribution in the age of electronic commerce," Industrial Marketing Management, vol. 31, no. 2, pp. 95-102, 2002.

[36] E. Brynjolfsson, Y. J. Hu, and M. D. Smith, "From niches to riches: anatomy of the long tail," Social Science Electronic Publishing, vol. 47, no. 4, pp. 67-71, 2006.

[37] D.-Q. Yao, X. Yue, X. Wang, and J. J. Liu, "The impact of information sharing on a returns policy with the addition of a direct channel," International Journal of Production Economics, vol. 97, no. 2, pp. 196-209, 2005.

[38] Y. Liang and X. Sun, "Product green degree, service freeriding, strategic price difference in a dual-channel supply chain based on dynamic game," Optimization, vol. 1, pp. 1-42, 2020.

[39] T.-H. Chen, "Effects of the pricing and cooperative advertising policies in a two-echelon dual-channel supply chain," Computers and Industrial Engineering, vol. 87, pp. 250-259, 2015.

[40] S. K. Mukhopadhyay, D.-Q. Yao, and X. Yue, "Information sharing of value-adding retailer in a mixed channel hi-tech supply chain," Journal of Business Research, vol. 61, no. 9, pp. $950-958,2008$.

[41] L. Zhang and J. Wang, "Coordination of the traditional and the online channels for a short-life-cycle product," European Journal of Operational Research, vol. 258, pp. 639-651, 2017.

[42] Y. Du, M. Cui, and J. Su, "Implementation processes of online and offline channel conflict management strategies in manufacturing enterprises: a resource orchestration perspective," International Journal of Information Management, vol. 39, pp. 136-145, 2018.

[43] A. A. Tsay and N. Agrawal, "Channel conflict and coordination in the e-commerce age," Production and Operations Management, vol. 13, no. 1, pp. 93-110, 2009.

[44] G. Xu, B. Dan, X. Zhang, and C. Liu, "Coordinating a dualchannel supply chain with risk-averse under a two-way revenue sharing contract," International Journal of Production Economics, vol. 147, pp. 171-179, 2014.

[45] J. Xie, W. Zhang, L. Liang, Y. Xia, J. Yin, and G. Yang, “The revenue and cost sharing contract of pricing and servicing policies in a dual-channel closed-loop supply chain," Journal of Cleaner Production, vol. 191, pp. 361-383, 2018.

[46] I. Biswas and B. Avittathur, "Channel coordination using options contract under simultaneous price and inventory competition," Transportation Research Part E: Logistics and Transportation Review, vol. 123, pp. 45-60, 2019.

[47] A. Ahmadi-Javid and P. Hoseinpour, "On a cooperative advertising model for a supply chain with one manufacturer and one retailer," European Journal of Operational Research, vol. 219, no. 2, pp. 458-466, 2012.

[48] Y.-C. Tsao and G.-J. Sheen, "Effects of promotion cost sharing policy with the sales learning curve on supply chain coordination," Computers and Operations Research, vol. 39, no. 8, pp. 1872-1878, 2012.

[49] M. Leng and M. Parlar, "Game-theoretic analyses of decentralized assembly supply chains: non-cooperative equilibria vs. coordination with cost-sharing contracts," European Journal of Operational Research, vol. 204, no. 1, pp. 96-104, 2010.

[50] T. Chakraborty, S. S. Chauhan, and M. Ouhimmou, "Costsharing mechanism for product quality improvement in a supply chain under competition," International Journal of Production Economics, vol. 208, pp. 566-587, 2019.

[51] Y.-W. Zhou, J. Guo, and W. Zhou, "Pricing/service strategies for a dual-channel supply chain with free riding and servicecost sharing," International Journal of Production Economics, vol. 196, pp. 198-210, 2018.

[52] G. P. Cachon and M. A. Lariviere, "Capacity choice and allocation: strategic behavior and supply chain performance," Management Science, vol. 45, no. 8, pp. 1091-1108, 1999.

[53] Y. Zhao and M. N. Katehakis, "On the structure of optimal ordering policies for stochastic inventory systems with minimum order quantity," Probability in the Engineering and Informational Sciences, vol. 20, no. 2, pp. 257-270, 2006.

[54] J. Hou, A. Z. Zeng, and L. Sun, "Backup sourcing with capacity reservation under uncertain disruption risk and minimum order quantity," Computers and Industrial Engineering, vol. 103, pp. 216-226, 2016.

[55] E. Porras and R. Dekker, "An efficient optimal solution method for the joint replenishment problem with minimum order quantities," European Journal of Operational Research, vol. 174, no. 3, pp. 1595-1615, 2006.

[56] W. A. Feng, C. Adb, and D. Lw, "Supply chain coordination with competing suppliers under price-sensitive stochastic demand," International Journal of Production Economics, vol. 234, 2021.

[57] A. A. Tsay, "The quantity flexibility contract and suppliercustomer incentives," Management Science, vol. 45, no. 10, pp. 1339-1358, 1999.

[58] B. Tomlin, "Capacity investments in supply chains: sharing the gain rather than sharing the pain," Manufacturing and Service Operations Management, vol. 5, no. 4, pp. 317-333, 2003.

[59] A. Halati and Y. He, "Analysis of supply chains with quantity based fixed incentives," European Journal of Operational Research, vol. 202, no. 1, pp. 214-222, 2010.

[60] J. Zhang and R. Q. Zhang, "Supply chain structure in a market with deceptive counterfeits," European Journal of Operational Research, vol. 240, no. 1, pp. 84-97, 2015.

[61] Y. Liu, F. Qin, M. J. Fry, and A. S. Raturi, "Multi-period modeling of two-way price commitment under price-dependent demand," European Journal of Operational Research, vol. 221, no. 3, pp. 546-556, 2012.

[62] J. Zhang, Q. Gou, L. Liang, and Z. Huang, "Supply chain coordination through cooperative advertising with reference price effect," Omega, vol. 41, no. 2, pp. 345-353, 2013.

[63] T. Xiao, Y. Xia, and G. P. Zhang, "Strategic outsourcing decisions for manufacturers that produce partially substitutable products in a quantity-setting duopoly situation," Decision Sciences, vol. 38, no. 1, pp. 81-106, 2007.

[64] G. P. Cachon and A. G. Kök, "Competing manufacturers in a retail supply chain: on contractual form and coordination," Management Science, vol. 56, no. 3, pp. 571-589, 2010.

[65] Y. H. Albert, S. Tong, and H. Zhang, "Sharing demand information in competing supply chains with production diseconomies," Management Science, vol. 57, no. 3, pp. 566-581, 2011.

[66] E. Adida and G. Perakis, "The effect of supplier capacity on the supply chain profit," Annals of Operations Research, vol. 223, no. 1, pp. 1-52, 2014. 
[67] D. Ghosh and J. Shah, "Supply chain analysis under green sensitive consumer demand and cost sharing contract," International Journal of Production Economics, vol. 164, pp. 319-329, 2015.

[68] Y. Zha, J. Zhang, X. Yue, and Z. Hua, "Service supply chain coordination with platform effort-induced demand," Annals of Operations Research, vol. 235, no. 1, pp. 785-806, 2015. 